\title{
Large internal waves in Massachusetts Bay transport sediments offshore
}

\author{
B. Butman ${ }^{\mathrm{a}, *}$, P.S. Alexander ${ }^{\mathrm{b}}$, A. Scotti ${ }^{\mathrm{c}, 1}$, R.C. Beardsley ${ }^{\mathrm{c}}$, S.P. Anderson ${ }^{\mathrm{c}, 2}$ \\ ${ }^{\mathrm{a}}$ US Geological Survey, 384 Woods Hole Road, Woods Hole, MA 02543, USA \\ ${ }^{\mathrm{b}}$ Integrated Statistics, Woods Hole, MA 02543, USA \\ ${ }^{\mathrm{c}}$ Department of Physical Oceanography, Woods Hole Oceanographic Institution, Woods Hole, MA 02543, USA
}

Available online 26 September 2006

\begin{abstract}
A field experiment was carried out in Massachusetts Bay in August 1998 to assess the role of large-amplitude internal waves (LIWs) in resuspending bottom sediments. The field experiment consisted of a four-element moored array extending from just west of Stellwagen Bank (90-m water depth) across Stellwagen Basin (85- and 50-m water depth) to the coast (24-m water depth). The LIWs were observed in packets of 5-10 waves, had periods of 5-10 min and wavelengths of 200-400 m, and caused downward excursions of the thermocline of as much as $30 \mathrm{~m}$. At the $85-\mathrm{m}$ site, the current measured $1 \mathrm{~m}$ above bottom (mab) typically increased from near 0 to $0.2 \mathrm{~m} / \mathrm{s}$ offshore in a few minutes upon arrival of the LIWs. At the 50-m site, the near-bottom offshore flow measured 6 mab increased from about 0.1 to $0.4-0.6 \mathrm{~m} / \mathrm{s}$ upon arrival of the LIWs and remained offshore in the bottom layer for $1-2 \mathrm{~h}$. The near-bottom currents associated with the LIWs, in concert with the tidal currents, were directed offshore and sufficient to resuspend the bottom sediments at both the 50- and $85-\mathrm{m}$ sites. When LIWs are present, they may resuspend sediments for as long as 5 hours each tidal cycle as they travel westward across Stellwagen Basin. At $85-\mathrm{m}$ water depth, resuspension associated with LIWs is estimated to occur for about 0.4 days each summer, about the same amount of time as caused by surface waves.
\end{abstract}

Published by Elsevier Ltd.

Keywords: Internal waves; Sediment transport; Massachusetts Bay; Stellwagen bank

\footnotetext{
*Corresponding author.

E-mail addresses: bbutman@usgs.gov (B. Butman), palexander@usgs.gov (P.S. Alexander), ascotti@unc.edu (A. Scotti), rbeardsley@whoi.edu (R.C. Beardsley), steve@horizonmarine.com (S.P. Anderson).

${ }^{1}$ Present address: Department of Marine Sciences, University of North Carolina, Chapel Hill, NC 27599, USA.

${ }^{2}$ Present address: Horizon Marine, Inc., Marion, MA 02738, USA
}

\section{Introduction}

The distribution of surficial sediment in Massachusetts Bay (Fig. 1) reflects the topography, the processes that resuspend and transport sediments, and the geologic history of the region. Stellwagen Bank and Jeffreys Ledge are shallow banks (20-40 $\mathrm{m}$ water depth) covered with sand and gravel that have been winnowed by waves and currents since the last rise in sea level. Similarly, the inner shelf along the western shore of Massachusetts Bay 


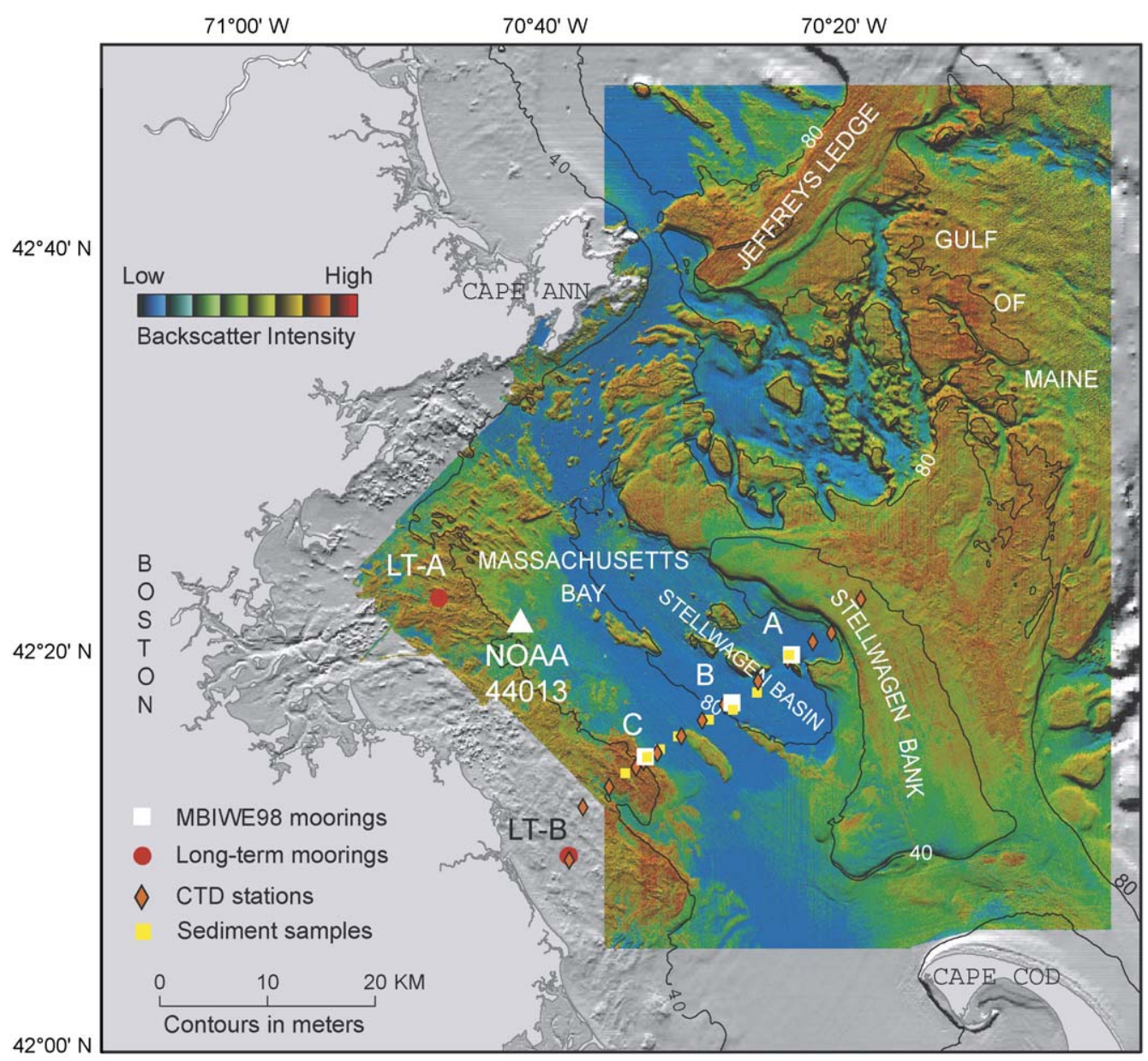

Fig. 1. Backscatter intensity (colored area) and shaded relief topography of the coastal region to the east of Boston (from Butman et al., 2004a). Red indicates high backscatter intensity material (typically sand, gravel and rock); blue indicates low backscatter intensity material (typically silt and clay). A, B and C are the locations of the moorings deployed as part of MBIWE98. LT-A and LT-B are the USGS/ MWRA long-term monitoring sites. NOAA 44013 is the location of the surface wave measurements.

at water depths shallower than $40-50 \mathrm{~m}$ is covered with sand, gravel and rock. Stellwagen Basin, the deepest part of Massachusetts Bay, is $80-90 \mathrm{~m}$ deep and is floored with fine-grained mud. The basin is generally considered to be a tranquil long-term depositional site for sediments winnowed from the inshore areas and the shallow banks (Tucholke and Hollister, 1973; Knebel and Circe, 1995). Sediment accumulation rates are about $0.001 \mathrm{~m} /$ year (Crusius et al., 2004). Along the western shore of Massachusetts Bay, the transition from mud to coarser sediments occurs at about the $50-\mathrm{m}$ isobath. This transition is especially abrupt, occurring over a few hundred meters, along a $8-\mathrm{km}$ section of the coast centered near $42^{\circ} 14.5^{\prime} \mathrm{N}, 70^{\circ} 33.5^{\prime} \mathrm{W}$ (near Site C, Fig. 1).
A well-recognized mechanism for the resuspension of bottom sediments in shallow coastal areas is bottom stress associated with surface waves. In Massachusetts Bay surface waves associated with winter storms, particularly waves that enter from the Gulf of Maine generated by storms with winds from the northeast, are sufficiently large to resuspend bottom sediments in water depths shallower than about $50 \mathrm{~m}$. It is hypothesized that these waves resuspend sediments along the shallow western shore of Massachusetts Bay and from the top of Stellwagen Bank. Along the western shore, the currents driven by the winds from the northeast carry the sediments southeastward toward Cape Cod Bay and offshore into Stellwagen Basin where they accumulate (Butman et al., 2005b). Elevated 
levels of contaminants, hypothesized to be transported from the Boston metropolitan region in this transport pattern, are found in the sediments of Cape Cod Bay and Stellwagen Basin (Ravizza and Bothner, 1996).

The existence of large-amplitude internal waves (LIWs) in Massachusetts Bay was first described by Halpern (1971), with further investigations by Haury et al. (1979, 1983), Chereskin (1983), Trask and Briscoe (1983), and Scotti and Pineda (2004). The waves are generated by interaction of the barotropic tide with Stellwagen Bank in summer when the water column is stratified. LIWs propagate westward into the bay on the flood (westward flowing) tide at about $0.5 \mathrm{~m} / \mathrm{s}$; these waves of depression are observed in packets of 5-10 waves, have periods of 5-10 min, and cause downward excursions of the thermocline of as much as $30 \mathrm{~m}$. Signatures of the internal wave packets have been observed in Synthetic Aperture Radar (SAR) images but not in water shallower than about $40 \mathrm{~m}$, approximately where the thermocline depth reaches half the water depth (Trask and Briscoe, 1983). Scotti and Pineda (2004) observed waves of elevation at $25-\mathrm{m}$ water depth, presumably morphed from the waves of depression observed in Stellwagen Basin.

The Massachusetts Bay Internal Wave Experiment (MBIWE98) was carried out to characterize the LIWs near the generation region, in the area of propagation, and in the area of dissipation, and to investigate the resuspension and transport of bottom sediments caused by these waves. This paper addresses three questions: (1) do the LIWs resuspend the fine-grained sediments occurring in Stellwagen Basin; (2) do the LIWs transport sediments and associated contaminants offshore to Stellwagen Basin; and (3) do the LIWs play a role in the sharp transition from coarse to fine-grained sediments at about $50-\mathrm{m}$ water depth that occurs along the western shore of Massachusetts Bay? This is the first investigation of the role of the LIWs in resuspending and transporting sediments.

Several papers present additional analyses and interpretations of the data collected in the MBIWE98. Scotti et al. (2005) present a beam-toearth coordinate transformation to determine the currents measured by an ADCP in a field of shortwavelength internal waves like those observed in Massachusetts Bay. Descriptions of the MBIWE98 moored array and hydrographic data may be found in a data report by Butman et al. (2006). Grosenbaugh et al. (2002) report on the performance of the MBIWE98 horizontal array.

Internal waves are ubiquitous in the coastal ocean and have been observed using moored instrumentation and by remote sensing (Global Ocean Associates, 2004). However, direct observations of nearbottom currents and sediment resuspension and/or transport by these waves are limited. Butman et al. (1979) documented near-bottom offshore currents associated with LIWs in the mid-Atlantic Bight, but they were not strong enough to resuspend the bottom sediments at $65-\mathrm{m}$ water depth. On the southern flank of Georges Bank, Butman (1987) measured near-bottom flow and documented episodic sediment resuspension and ripple formation by LIWs at 85-m water depth. At other locations on Georges Bank, the currents associated with LIWs were almost never strong enough to cause sediment movement alone, but when superimposed on tidal and other currents, they were a major cause of infrequent sediment movement in summer. In both these studies, the near-bottom currents associated with the LIWs were directed offshore. In Santa Monica Bay, CA, Noble and Xu (2003) describe near-bottom off-shelf transport by internal bores with near-bottom velocities of $0.3-0.4 \mathrm{~m} / \mathrm{s}$ and attribute the coarse sediments found in a band along the shelf break to winnowing by these currents. Shorter-term observations of LIW events on the Palos Verdes shelf (Bogucki et al., 1997), on the Oregon shelf (Klymak and Moum, 2003) and offshore of Oceanside California (Johnson et al., 2001) show increased near-bottom suspended-sediment concentrations associated with the passage of various LIWs.

Several characteristics of sediment transport by LIWs emerge from these field observations. First, the currents associated with LIWs are typically aligned in the cross-shelf direction, as the waves typically propagate across the shelf from deep to shallow water. The near-bottom currents are usually asymmetric (offshore for a wave of depression, onshore for a wave of elevation), and thus the LIWs provide an organized mechanism for onshore/offshore transport of sediments and materials. These characteristics are in contrast to the wind-driven currents where the strongest currents are typically along-shelf, or the symmetrical cross-shelf tidal currents. Second, the effect of LIWs may be stronger on the outer and mid-shelf region and weaker in shallow water inshore of a dissipation 
region. The LIW dissipation region may be particularly energetic. This decrease in strength is in contrast to the influence of surface waves, a wellestablished major cause of sediment resuspension on the continental shelf, that is typically largest in shallow water. Third, although the currents associated with LIWs have generally been observed to occur a small fraction of the time, they are often large enough, especially in concert with tidal and other flows, to episodically scour the sea floor and resuspend bottom sediments. Finally, although the ability of LIWs to resuspend and transport sediments is established, the relative rates and long-term effects of these processes on the regional geology (such as Cacchione et al., 2002; Noble and $\mathrm{Xu}$, 2003) or on the long-term fate of particles or animals (for example Pineda, 1991) have received less attention.

\section{Field experiment}

The MBIWE98, carried out from August 3 to September 2, 1998, consisted of a moored array experiment and hydrographic surveys. Sediment sampling and bottom photography were carried out in July 1999.

\subsection{MBIWE98 moored array}

The moored array consisted of instrumented moorings deployed at 3 stations spaced across Massachusetts Bay aligned along 55-245 (Figs. 1 and 2). Site A, located at $42^{\circ} 19.9^{\prime} \mathrm{N}, 70^{\circ} 23.5^{\prime} \mathrm{W}$ about $5 \mathrm{~km}$ from the western edge of Stellwagen Bank at $90-\mathrm{m}$ water depth, was placed to provide a description of the LIWs near the generation region. Site A was instrumented at 10, 20, 30, 40 and 50-m depth with temperature and conductivity sensors on a surface mooring. Site B, located at $42^{\circ} 17.5^{\prime} \mathrm{N}, 70^{\circ}$ $27.3^{\prime} \mathrm{W}$, was in the center of Stellwagen Basin at 85 $\mathrm{m}$ water depth, approximately $12 \mathrm{~km}$ from the western edge of Stellwagen Bank and $7.1 \mathrm{~km}$ from Site A. Site B is near the location of previous observations of the LIWs made by Halpern (1971) and Haury et al. (1979). Site B was instrumented from the surface to $1 \mathrm{~m}$ above bottom (mab) with an array of temperature, conductivity, current, light transmission and pressure sensors deployed on surface and subsurface moorings and on a bottom tripod. A 'horizontal' mooring deployed at Site B provided closely spaced measurements in both the horizontal (order $20 \mathrm{~m}$ ) and vertical $(5 \mathrm{~m}$ ) (see Grosenbaugh et al. (2002) for a description of this mooring). Site $\mathrm{C}$ was located at $42^{\circ} 14.7^{\prime} \mathrm{N}$,

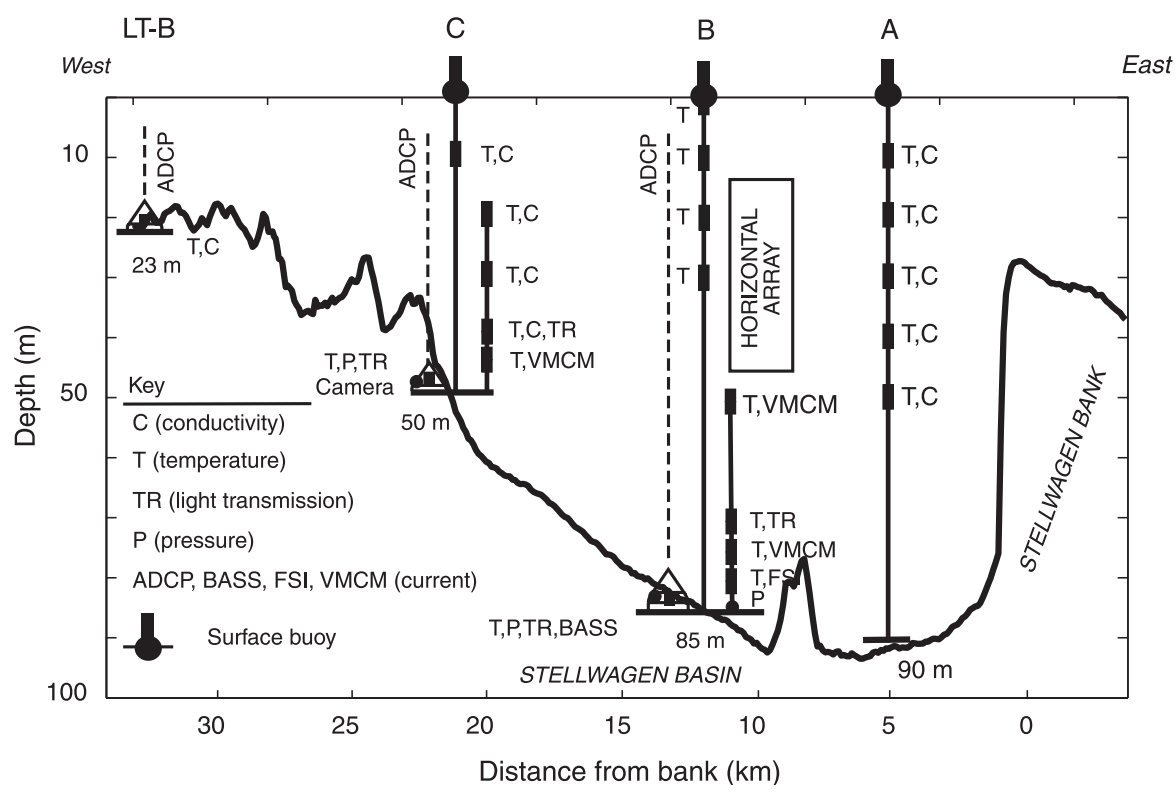

Fig. 2. Cross section of Massachusetts Bay showing location and type of instruments deployed at sites A, B, C and LT-B to observe the packets of LIWs as they propagate westward from Stellwagen Bank across Stellwagen Basin to the western shore of Massachusetts Bay. Currents were measured with four types of instruments: RDI acoustic Doppler current profiler (ADCP), FSI acoustic current meters, vector-measuring current meter (VMCM), and BASS acoustic travel time sensors. The near-bottom instruments discussed in this paper were deployed at Sites B and C. 
$70^{\circ} 33.2^{\prime} \mathrm{W}$ at $50-\mathrm{m}$ water depth, just offshore of the transition from coarse to fine-grained sediments and $9.5 \mathrm{~km}$ from Site B. Temperature, conductivity, current, pressure, and light transmission sensors were deployed on a surface and subsurface mooring, and on a small bottom tripod. Time-series photographs were obtained every hour at Site $\mathrm{C}$ by means of a $35 \mathrm{~mm}$ camera on the bottom tripod. In order to resolve the high-frequency motions associated with the LIWs, instruments in the array were set to sample every $15 \mathrm{~s}$ (for some temperature and conductivity observations), or every minute (for most current observations and other temperature and conductivity observations). The ADCP measurements were processed to account for the spatial differences in the current over the spacing of the acoustic beams during passage of the LIWs using the method described in Scotti et al. (2005).

\subsection{Long-term observations}

Moorings were also in place during MBIWE98 at two additional sites in western Massachusetts
Bay (Site LT-A at $42^{\circ} 22.6^{\prime} \mathrm{N}, 70^{\circ} 47.0^{\prime} \mathrm{W}$ and Site LT-B at $42^{\circ} 9.7^{\prime} \mathrm{N}, 70^{\circ} 38.4^{\prime} \mathrm{W}$ ) (Fig. 1) as part of a long-term monitoring program carried out by the USGS in cooperation with the Massachusetts Water Resources Authority (Butman et al., 2004b). Instrumentation at Site LT-A included a subsurface mooring with a vector measuring current meter (VMCM), temperature, conductivity, and transmissometer at $10 \mathrm{mab}$, and a bottom tripod with upward-looking ADCP and near-bottom current, temperature, conductivity, pressure, and light transmission sensors and camera. On several deployments a McLane Labs Water Transfer System (WTS 6-24-47FH) was deployed on the tripod at Station A to collect in situ suspended particulate matter. An upward looking ADCP was deployed on a bottom tripod at Site LT-B. The sampling rate of the near-bottom instruments (VMCM and tripod sensors) at LT-A was $3.75 \mathrm{~min}$, the ADCP's at LT-A and LT-B sampled for $5 \mathrm{~min}$ every $15 \mathrm{~min}$. Observations have been made at LT-A since 1990 and at LT-B since 1997.

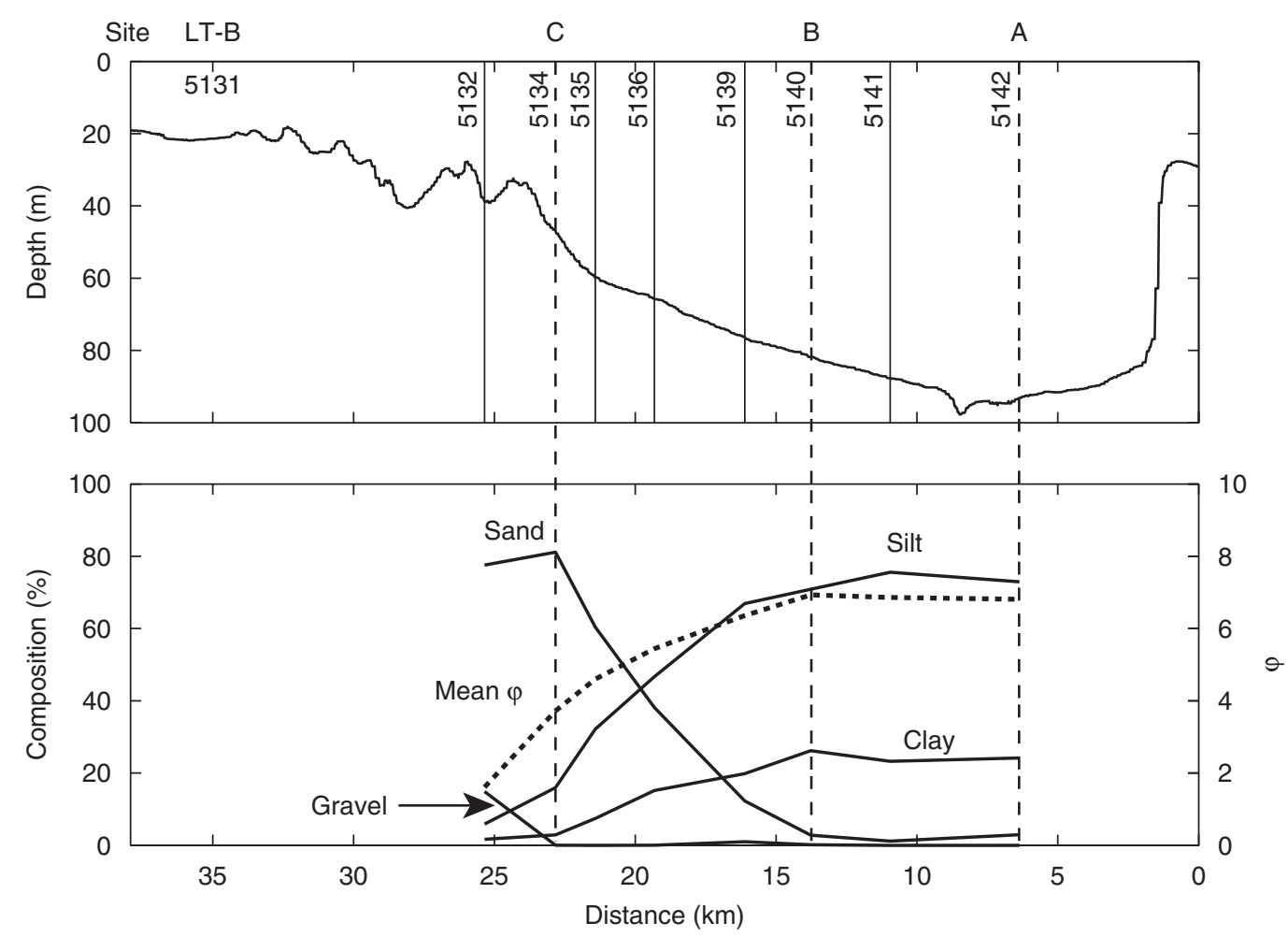

Fig. 3. Top panel: Water depth, location of sediment sampling stations (numbered 5131-5142), and MBIWE98 mooring sites along a transect from the western edge of Massachusetts Bay to Stellwagen Bank $(x=0)$. Lower panel: Bottom sediment texture (mean phi $=-\log _{2}$ (mean grain diameter in $\left.\mathrm{mm}\right)$ ), and percent gravel, sand, silt and clay). The seafloor at station 5131 was gravel and no sediment sample could be obtained. 


\subsection{Hydrography}

Three hydrographic cruises were conducted during the moored array experiment to map the temperature, salinity, and suspended-sediment fields across Massachusetts Bay. Sections of temperature and salinity were made along a transect through the moorings (Fig. 1) on August 6 and August 20, 1998 on the FV Christopher Andrew, and sections of temperature, salinity and light transmission were made between August 31 and September 2, 1998, during mooring recovery, on the RV Argo Maine. Temperature and salinity on the RV Argo Maine were measured with a SeaBird 9/11CTD and light transmission with a $0.25-\mathrm{m}$ path-length Chelsea AlphaTrackA transmissometer. Beam attenuation $(1 / \mathrm{m})$ was computed as $-\ln (\%$ light transmission $)$.

\subsection{Wave and wind observations}

Surface wave observations from NOAA Buoy 44013 , located at $42^{\circ} 21.23^{\prime} \mathrm{N}, 70^{\circ} 41.48^{\prime} \mathrm{W}$ (Fig. 1), were obtained from the National Data Buoy Center for the period 1996-2005. Bottom wave-orbital velocities were calculated from the surface wave spectra using linear wave theory and then used to calculate bottom stress following Madsen (1994).

\subsection{Synthetic Aperture Radar (SAR) images}

SAR images of Massachusetts Bay at 25-m resolution were obtained by the Radarsat-1 satellite on August 17, 27 and 30, 1998 at 10:57, 22:37, and 22:24 h GMT, respectively. Under favorable conditions, changes in the sea surface roughness caused by the divergence in the surface flow associated with the LIWs can provide a picture of the spatial distribution of the waves (Gasparovic et al., 1986, 1988). LIW features in the SAR images were identified, traced by hand and combined into a composite figure.

\subsection{Site characterization}

The sea floor of Massachusetts Bay has been mapped using a multibeam sea floor mapping
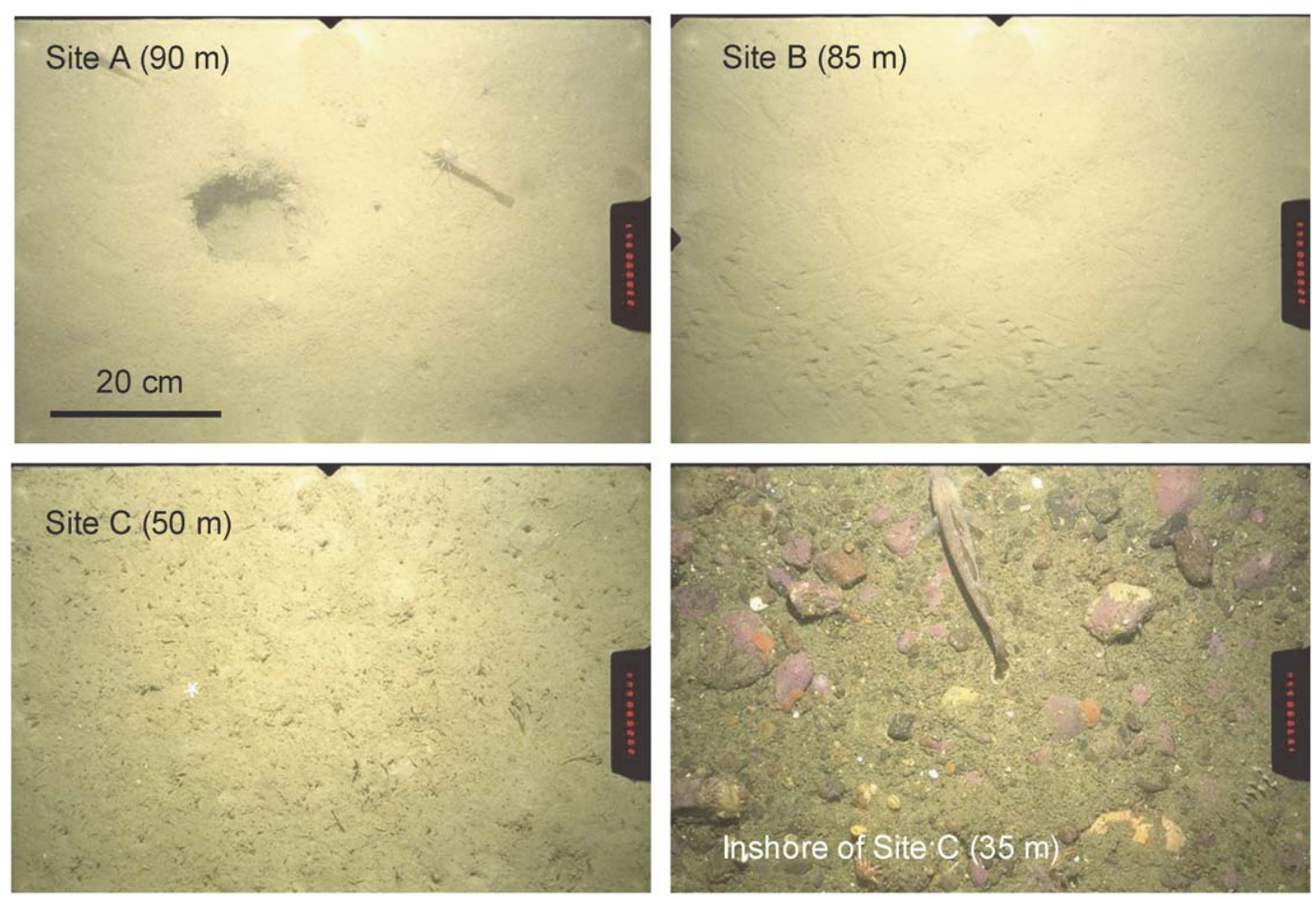

Fig. 4. Photographs of the sea floor at Site A (90-m water depth), Site B (85-m water depth), Site C (50-m water depth) and inshore of Site $\mathrm{C}$ (35-m water depth). The pink color on the cobbles at the site inshore of Site $\mathrm{C}$ is a calcareous algae that grows on cobbles or boulders in water depths shallower than about $25 \mathrm{~m}$ where sufficient light reaches the sea floor; the presence of the algae suggests that these cobbles are not frequently overturned. The black rectangle on the right side of the images is a photo identifier. 
system, providing bathymetry and backscatter intensity at a spatial resolution of $10 \mathrm{~m}$ (Butman et al., 2004a) (Fig. 1). Photographs, videos, and samples of the sea floor were obtained in July 1999 from the FV Isabel $S$ (Gutierrez et al., 2001) along a transect (Fig. 1) between the MBIWE98 mooring locations using the USGS SEABOSS sampling system (Valentine et al., 2000). Sediments were processed according the procedures outlined in Poppe et al. (2000) and classified according to the scheme of Shepard (1954).

\subsection{Suspended-sediment concentration}

The beam attenuation calculated from the transmissometers deployed on the moorings and used for the hydrographic section are used to provide a qualitative measure of the change in suspendedsediment concentration over time and space. The attenuation of a suspension of particles increases with the inverse of the diameter of the suspended sediment, and attenuation is most sensitive to the finest sizes in the population of suspended sediment (Baker and Lavelle, 1984; Moody et al., 1987; Wiberg et al., 1994). A quantitative measure of sediment concentration from the transmission measurements at a minimum requires knowledge of the distribution of grain sizes in suspension and was beyond the scope of this study. For a given sediment size, however, attenuation increases linearly with increasing sediment concentration. The pumped water samples obtained during resuspension events at LT-A suggest about $4 \mathrm{mg} / \mathrm{l}$ suspended-sediment concentration per $\mathrm{m}^{-1}$ of beam attenuation (M. Bothner, personal communication). Field calibrations of a Sea Tech transmissometer (identical to that used in MBIWE98 moored array) based on hydrographic profiles obtained during calm conditions in the New York Bight (Harris et al., 2003) suggest a proportionality of about $2 \mathrm{mg} /$ $1 \mathrm{~m}^{-1}$ of beam attenuation. Using these calibrations as a guide, changes in beam attenuation of $1-2 \mathrm{~m}^{-1}$, as measured in MBIWE98, indicate sediment concentrations of a few $\mathrm{mg} / 1$.

\section{Results}

\subsection{Geologic setting}

Backscatter intensity from the multibeam sonar surveys shows generally high backscatter intensity on the shelf in water depths less than about $50 \mathrm{~m}$
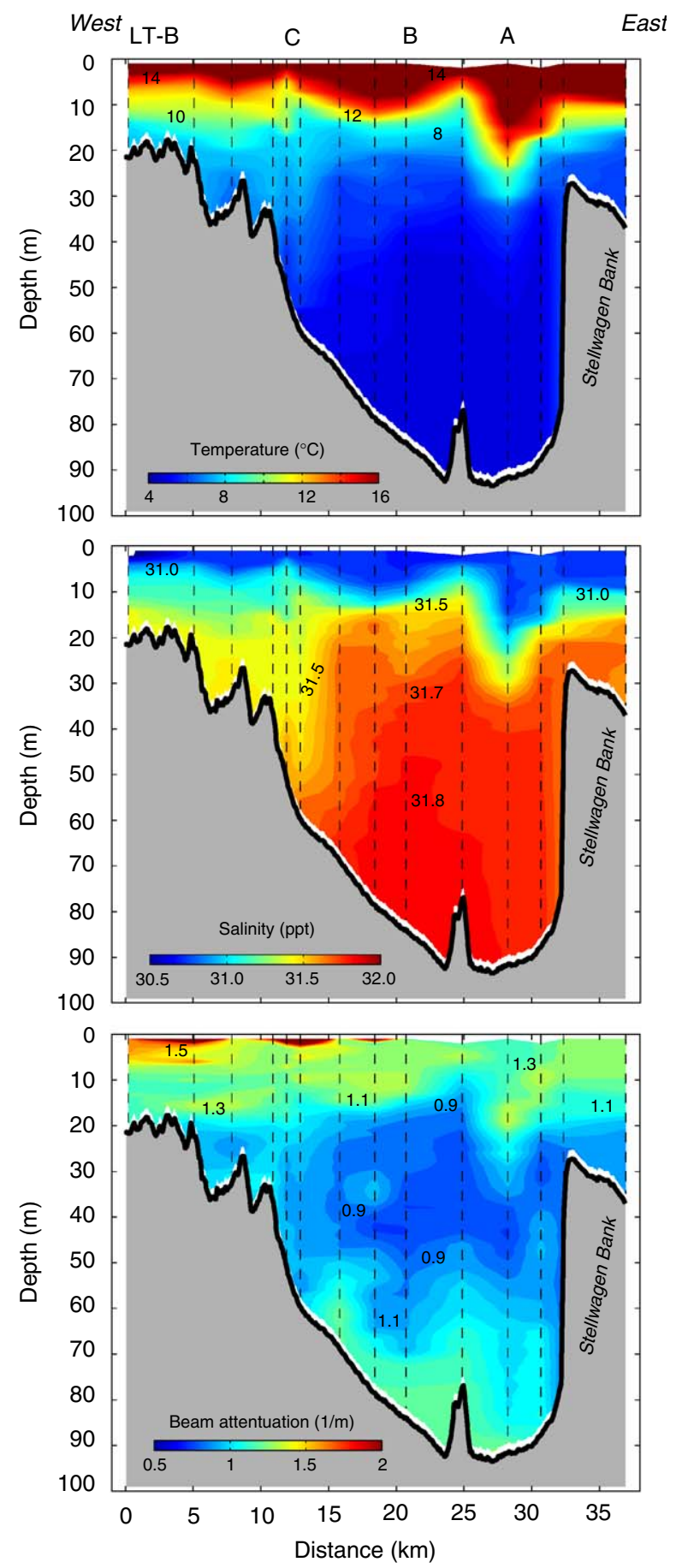

Fig. 5. Temperature, salinity, and beam attenuation on September 1, 1998 along the MBIWE98 mooring transect (start 11:46 after low water at inshore end of section, end at 15:48 after low water at offshore end). Vertical dashed lines show location of CTD stations. See Fig. 1 for station locations. 

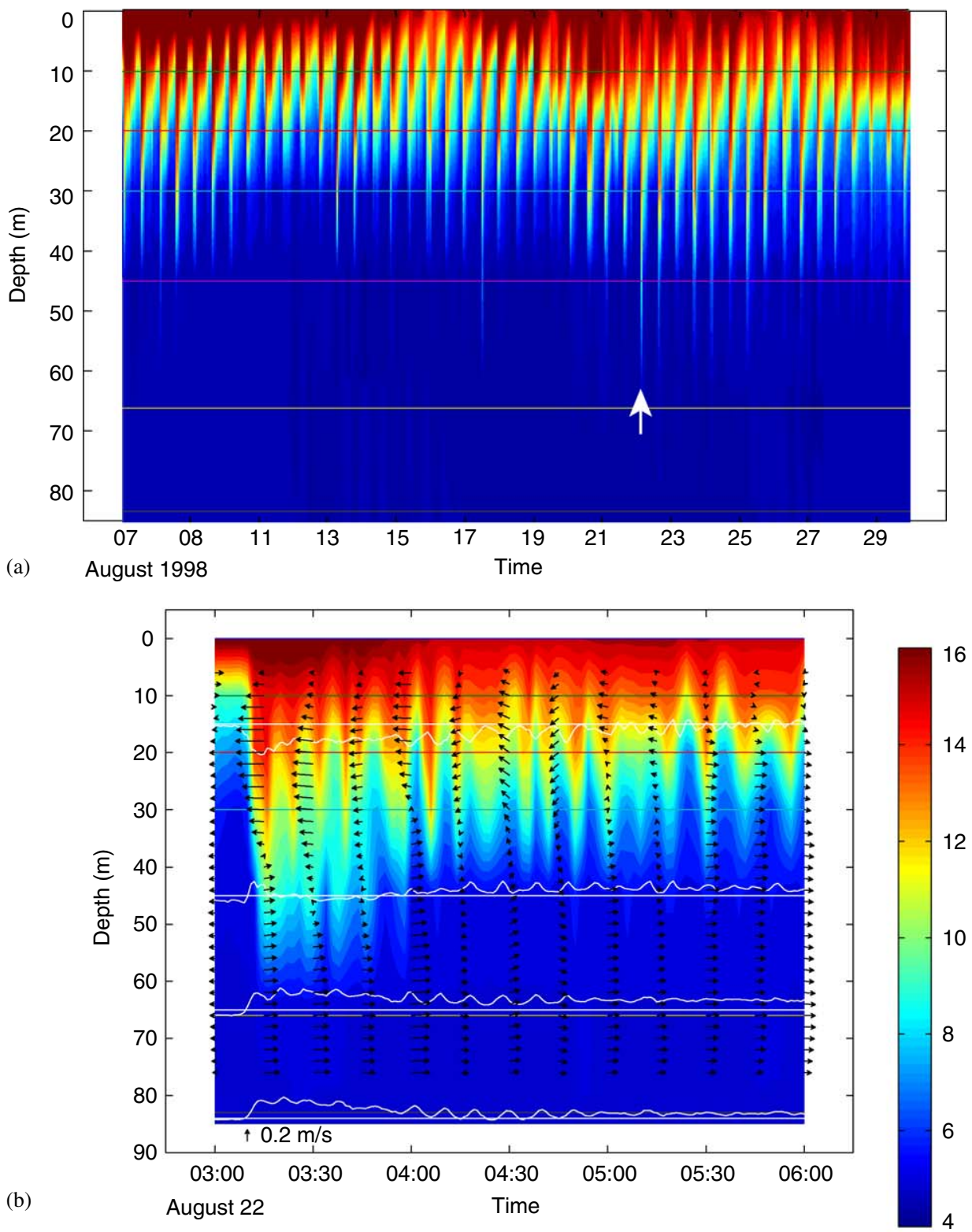

(b)
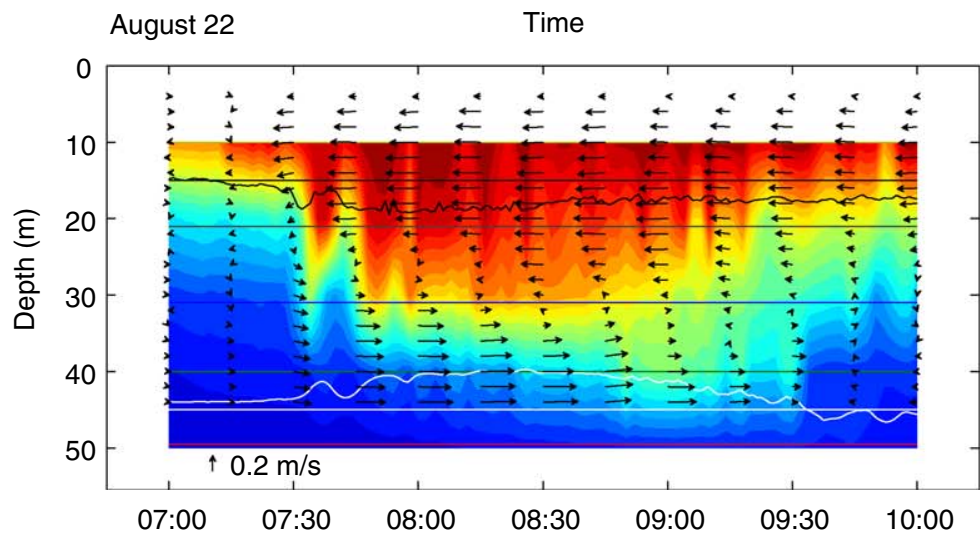

$\mathrm{T}\left({ }^{\circ} \mathrm{C}\right)$

(c) August 22

Time 
along the western shore of Massachusetts Bay, and low backscatter intensity in deeper water (Fig. 1). Along the mooring transect, sediment texture becomes increasingly finer offshore (Fig. 3). On the shelf at 40-m water depth (station 5132), the sediment is about $15 \%$ gravel, $78 \%$ sand and $8 \%$ mud (mean $\varphi$ of 1.8 , gravel $>10 \%$ ). Photographs at other sites in this area of high backscatter intensity show a gravel pavement that could not be sampled with a grab sampler. At Site $\mathrm{C}$ at $49-\mathrm{m}$ water depth (station 5134), located about $300 \mathrm{~m}$ offshore (northeastward) of the sharp transition from high to moderate backscatter intensity, the sediment is about $81 \%$ sand and $19 \%$ silt plus clay (mean $\varphi$ of 3.7, classified as sand). At Site B at 84-m water depth (station 5140) and at Site A (station 5142) near the deepest part of Stellwagen Basin at 95-m water depth, backscatter intensity is low and the sediment is about 3\% sand and $97 \%$ silt plus clay (mean $\varphi$ of 6.8 , classified as clayey silt). Bottom photographs (Fig. 4) show a gravel pavement on the shelf (inshore of Site C) with patches of sand, sand with numerous tubeworms at Site C (station 5134), and muddy burrowed sediments in Stellwagen Basin near Sites A and B.

\subsection{Hydrography}

The hydrographic section made across Massachusetts Bay on September 1, 1998 shows a water column stratified by warm fresher water near the surface and colder saltier water near the bottom (Fig. 5) and is similar to the sections made on August 6 and 20, 1998. The pyncnocline is centered between 10 and $15 \mathrm{~m}$; the mean Brunt-Vasaila frequency at this depth for all stations occupied in the September cruise near Site B was about $0.0021 / \mathrm{s}$ (period of about $8 \mathrm{~min}$ ). The depression in the thermocline observed near Site A was due to a LIW. At Site C, an LIW was observed about $3 \mathrm{~h}$ prior to the hydrographic observations, so the structure reflects conditions following passage of an LIW. The beam attenuation section (Fig. 5) shows beam attenuation greater than $1.31 / \mathrm{m}$ in the surface waters shallower than about $15 \mathrm{~m}$, a core of lower beam attenuation water (less than $0.91 / \mathrm{m}$ ) between about 20 and $50 \mathrm{~m}$ in Stellwagen Basin, and an increase of beam attenuation of about $0.21 / \mathrm{m}$ (corresponding to an increase in suspended-sediment concentration of perhaps $0.2 \mathrm{mg} / \mathrm{l}$ ) from about $50 \mathrm{~m}$ to the bottom. The core of low-beam-attenuation water extends to the western flank of Stellwagen Bank. In the area surrounding Site $\mathrm{C}$ (between about 40 - and $60-\mathrm{m}$ water depth along the southwestern part of the section) warmer saltier water extends closer to the bottom compared to the water to the east. The relatively high beam attenuation near the surface is attributed to biological particles; the near-bottom increase in Stellwagen Basin is hypothesized to be the result of resuspension of bottom sediments associated with LIWs (see Section 3.4).

\subsection{Large-amplitude internal waves}

During MBIWE98, the temperature and current fluctuations observed at Sites A, B and C were dominated by LIW events (Figs. 6 and 7, Table 1). These events were characterized by a rapid depression of the thermocline followed by onshore flow at the surface and offshore flow at the bottom. The LIWs propagated to the southwest across Massachusetts Bay, regularly arriving at a fixed location every semidiurnal tidal cycle $(12.4 \mathrm{~h})$ (Table 1). Forty-nine packets of LIWs were observed at Site B between August 7 and August 31 (Fig. 7a). To simplify comparison of the LIW packets at the different sites, each wave packet was assigned a sequential event number based on the horizontal array data at Site B, with event 1 beginning on August 6 at 22:21 at Site A, August 7 at 1:23 at Site B, and August 7 at 6:21 at Site C. The packets

\footnotetext{
Fig. 6. (a) Temperature at Site B, August 7-30, 1998, contoured from observations obtained from instruments at 0, 10, 20, and 30 m (on the surface mooring), 45 and $70 \mathrm{~m}$ (on the subsurface mooring) and $84 \mathrm{~m}$ (on the bottom tripod). The white arrow marks the event observed on August 22 shown in Figs. 6b,7b and 7c; (b). Temperature at Site B, August 22, 0300-0600, contoured as in (6a). Superimposed is a time-series of current along $70-250^{\circ}$ (positive offshore toward $70^{\circ}$; negative onshore toward $250^{\circ}$ ) from current meters at $15,45,75$ and $84 \mathrm{~m}$ (white lines) and current every $15 \mathrm{~min}$ from the upward-looking ADCP on the bottom tripod (black arrows); (c). Temperature at Site C, August 20,0700-1000, contoured from observations obtained from instruments at $10 \mathrm{~m}$ (on the surface mooring), and at 21, 31 and $41 \mathrm{~m}$ (on the subsurface mooring) and at $49 \mathrm{~m}$ (on the bottom tripod). Superimposed is a time-series of current along $70-250^{\circ}$ (positive offshore toward $70^{\circ}$; negative onshore toward $250^{\circ}$ ) at $15 \mathrm{~m}$ from the ADCP (black line), current at $45 \mathrm{~m}$ from the VMCM (white line) and current every $15 \mathrm{~min}$ from the upward-looking ADCP deployed on the bottom tripod (black arrows). This is the same event observed at Site B approximately $4 \mathrm{~h}$ earlier (Fig. 6b).
} 
arrived at Sites A, B and C at $2.1 \pm 0.3,5.2 \pm 0.5$, and $10.0 \pm 1.1 \mathrm{~h}$ after low water at Site $\mathrm{B}$, respectively. The speed of travel of the packets between Sites A and B and Sites B and C was 0.63 and $0.54 \mathrm{~m} / \mathrm{s}$, respectively (uncorrected for advection). At Site B, based on the travel through the horizontal array, the packets traveled at about $0.64 \mathrm{~m} / \mathrm{s}$.

At Site B, the LIWs arrive during the last hour of the flood tide (on average about $5 \mathrm{~h}$ after low water) when the tidal current is weakly westward (onshore). When the waves arrive, the current speed measured 1 mab typically changes from less than
$0.05 \mathrm{~m} / \mathrm{s}$ onshore to $0.2-0.3 \mathrm{~m} / \mathrm{s}$ offshore in $1-2 \mathrm{~min}$. This rapid change in current speed and direction is then typically followed by a series of oscillations with periods of 5-10 min (Figs. 6b,7b and 7c); the near-bottom current, the sum of the eastwardflowing (ebb) tidal current and the LIW current, is eastward (offshore) during the entire LIW event. The oscillations at Site B were largest August 20-22 (packets 26-31). At Site C, the LIWs arrive near the end of the eastward-flowing ebb tide. When the waves arrive, the current speed measured $6 \mathrm{mab}$ typically increases from about $0.10 \mathrm{~m} / \mathrm{s}$ to the northeast (offshore) to greater than $0.30 \mathrm{~m} / \mathrm{s}$ toward
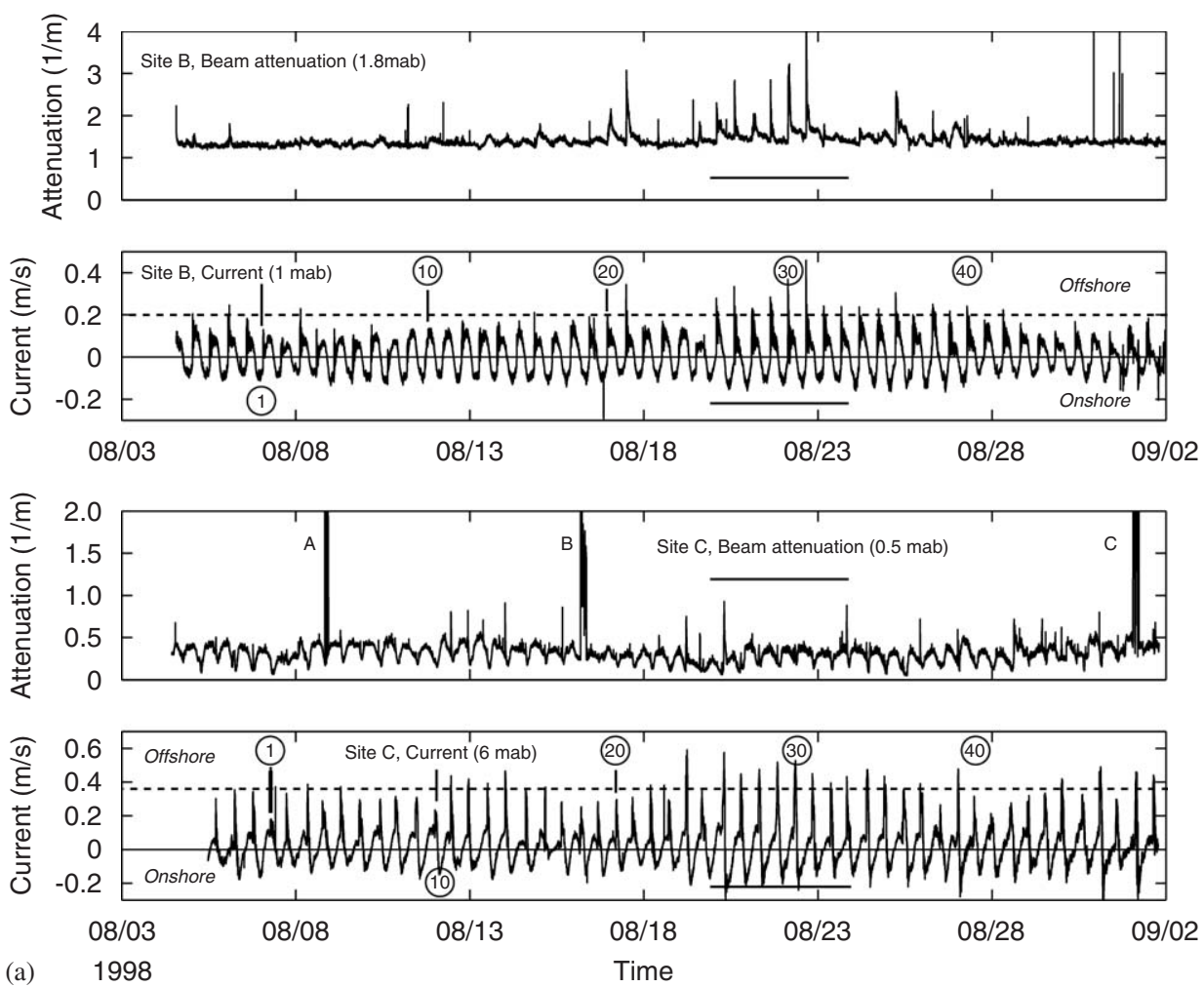

Fig. 7. (a) Time series of current $1 \mathrm{mab}$ (along 70-250 ) and beam attenuation $1.8 \mathrm{mab}$ at Site B and current $6 \mathrm{mab}\left(\mathrm{along} 70-250^{\circ}\right.$ ) and beam attenuation $0.54 \mathrm{mab}$ at Site $\mathrm{C}$ for the entire period of MBIWE98. Numbers in circles are event numbers as determined from analysis of horizontal array temperature observations. Events 26-31 are the largest observed at Site B. The horizontal line indicates the time period shown in Fig. 7 b. The dashed line at $0.2 \mathrm{~m} / \mathrm{s}$ on the Site B current panel and at $0.35 \mathrm{~m} / \mathrm{s}$ on the Site C current panel mark the sediment resuspension threshold. The increases in beam attenuation at Site C labeled A, B and C (and some of the other short-duration spikes at Sites B and C) are most likely caused by organisms in the transmissometer beam and are not associated with resuspension by currents. Note the well-defined pulses of offshore flow at Site C during the LIW events; (b). Time series of current 1 mab (along $70-250^{\circ}$ ) and beam attenuation $1.8 \mathrm{mab}$ at Site B and current $6 \mathrm{mab}$ (along 70-250 ) and beam attenuation $0.5 \mathrm{mab}$ at Site C for the period August 20-24, 1998. Numbers in circles are LIW packet numbers (see text). Near-bottom increases in beam attenuation occur at Sites B and C during the LIW events. Note the fluctuations in the near-bottom current associated with the LIWs at Site B and the pulse-like offshore flow at Site C. Vertical dashed lines mark the beginning of LIWs at Site B and the peak current at Site C. Horizontal dashed lines $(0.20 \mathrm{~m} / \mathrm{s}$ at Site B and $0.35 \mathrm{~m} / \mathrm{s}$ at Site C) mark the sediment resuspension thresholds. Arrows on Site C current panel indicate times of bottom photographs shown in Fig. 9. The horizontal black line marks the time period shown in Fig. 7c; (c). Time series of current 1 mab (along 70-250 ) and beam attenuation $1.8 \mathrm{mab}$ at Site B and current $6 \mathrm{mab}$ (along 70-250 ) and beam attenuation at 0.5 mab at Site C for August 22 , 1998 when the LIW currents were strongest at Site B. Vertical dashed lines mark the beginning of LIWs at Site B and the peak current at Site C. 

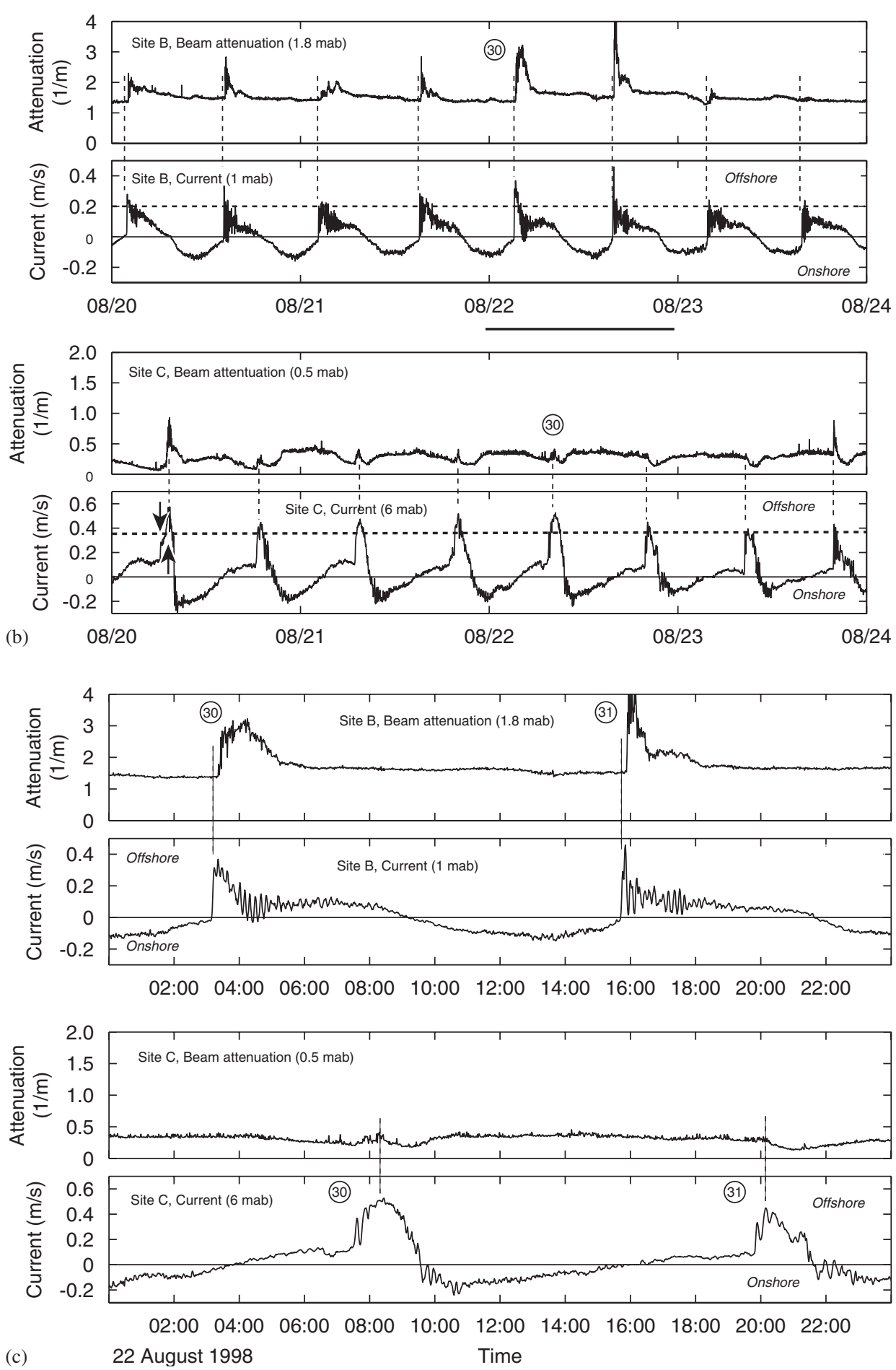

Fig. 7. (Continued)

the northeast (Figs. 6c,7b,7c). In some cases there are oscillations in the flow at Site $\mathrm{C}$ similar to those observed at Site B, but in most cases the flow remains steady to the northeast for $1-2 \mathrm{~h}$ following the arrival of the LIWs. The remarkably strong, pulse-like near-bottom offshore flow associated with the LIWs was observed at Site $\mathrm{C}$ throughout MBIWE98 (Fig. 7a). 
Table 1

Summary of characteristics of LIWs and sediment resuspension caused by LIWs and by surface waves in Massachusetts Bay

\begin{tabular}{|c|c|c|c|c|}
\hline & LT-B (25 m) & Site C $(50 \mathrm{~m})$ & Site B $(85 \mathrm{~m})$ & Site A $(90 \mathrm{~m})$ \\
\hline \multicolumn{5}{|l|}{ LIW characteristics } \\
\hline Arrival of LIWs after low water at Site B (hours) & $\begin{array}{l}\text { Not observed } \\
\text { in MBIWE }\end{array}$ & $10.0 \pm 1.1$ & $5.2 \pm 0.5$ & $2.1 \pm 0.3$ \\
\hline Time between arrival of LIWs (hours) & $\mathrm{n} / \mathrm{a}$ & $12.5 \pm 1.1$ & $12.5 \pm 0.7$ & $12.4 \pm 0.6$ \\
\hline Speed of LIWs (m/s) & $\mathrm{n} / \mathrm{a}$ & $\begin{array}{l}0.54 \\
\text { (B to C) }\end{array}$ & 0.64 & $\begin{array}{l}0.63 \\
\text { (A to } \mathrm{B})\end{array}$ \\
\hline Current threshold for sediment resuspension $(\mathrm{m} / \mathrm{s})$ & $\mathrm{n} / \mathrm{a}$ & $\begin{array}{l}0.35 \\
(6 \mathrm{mab})\end{array}$ & $\begin{array}{l}0.2 \\
(1 \mathrm{mab})\end{array}$ & $\mathrm{n} / \mathrm{a}$ \\
\hline$u *$ threshold for sediment resuspension $(\mathrm{m} / \mathrm{s})$ & $\mathrm{n} / \mathrm{a}$ & $\mathrm{n} / \mathrm{a}$ & 0.008 & $\mathrm{n} / \mathrm{a}$ \\
\hline \multicolumn{5}{|l|}{ Resuspension by LIWs } \\
\hline Threshold exceeded during MBIWE (\%) & $\mathrm{n} / \mathrm{a}$ & 2.2 & 0.7 & $\mathrm{n} / \mathrm{a}$ \\
\hline Threshold exceeded caused by LIWs (\%) & $\mathrm{n} / \mathrm{a}$ & 93 & 87 & $\mathrm{n} / \mathrm{a}$ \\
\hline Threshold exceeded caused by LIWs (days/summer) & $\mathrm{n} / \mathrm{a}$ & 1.3 & 0.4 & $\mathrm{n} / \mathrm{a}$ \\
\hline $\begin{array}{l}\text { Direction of near-bottom flow while threshold exceeded } \\
\text { during LIWs }\left(^{\circ}\right)\end{array}$ & $\mathrm{n} / \mathrm{a}$ & Toward 62 & Toward 79 & $\mathrm{n} / \mathrm{a}$ \\
\hline \multicolumn{5}{|l|}{ Resuspension by surface waves } \\
\hline $\begin{array}{l}\text { Time } u_{\mathrm{cw}}^{*}>0.008 \mathrm{~m} / \mathrm{s} \text { caused by surface waves in } \\
\text { winter }(\%)\end{array}$ & 39 & 11.2 & 1.4 & 1.0 \\
\hline $\begin{array}{l}\text { Time } u_{\mathrm{cw}}^{*}>0.008 \mathrm{~m} / \mathrm{s} \text { caused by surface waves in } \\
\text { winter (days) }\end{array}$ & 71 & 20.4 & 2.5 & 1.8 \\
\hline $\begin{array}{l}\text { Time } u_{\mathrm{cw}}^{*}>0.008 \mathrm{~m} / \mathrm{s} \text { caused by surface waves in } \\
\text { summer }(\%)\end{array}$ & 21 & 3.3 & 0.2 & 0.1 \\
\hline $\begin{array}{l}\text { Time } u_{\mathrm{cw}}^{*}>0.008 \mathrm{~m} / \mathrm{s} \text { caused by surface waves in } \\
\text { summer (days) }\end{array}$ & 38 & 6.0 & 0.4 & 0.2 \\
\hline
\end{tabular}

The $u *$ critical for fine-grained sediment resuspension at Site B was determined from the observed current threshold during MBIWE98 assuming a drag coefficient of 0.003 . A steady current of $0.07 \mathrm{~m} / \mathrm{s} 1 \mathrm{~m}$ above bottom (mab) was included in the calculation of bottom stress caused by surface waves to approximate the effect of tidal currents. To calculate days exceeded, LIWs were assumed present for 60 days in summer. Winter is defined as the period October through March and summer as the period April through September. n/a indicates not available.

SAR images collected during the MBIWE98 show ubiquitous surface roughness features associated with internal waves throughout Massachusetts Bay and the western Gulf of Maine (Fig. 8). The images on 17, 30 and 27 August were obtained at 5:20, 7:07, and 9:05 h, respectively, after low water at Site B. The images show three sets of LIWs along the MBIWE98 transect; one about $800 \mathrm{~m}$ east of Site B on 17 August, one about $5400 \mathrm{~m}$ east of Site $\mathrm{C}$ on 30 August, and a third about $1100 \mathrm{~m}$ east of Site C on 27 August (features 1, 2 and 3, respectively, in Fig. 8). The waves are ordered in distance southwestward from Stellwagen Bank by the time after low water at Site B. Assuming the average travel speed of $0.64 \mathrm{~m} / \mathrm{s}$, the waves on 17 August are predicted to arrive at Site B 21 min after the SAR image; they arrived $37 \mathrm{~min}$ after the image. Assuming the average travel speed of $0.54 \mathrm{~m} / \mathrm{s}$, the waves on 27 and 30 August are predicted to arrive at Site C 34 and $167 \mathrm{~min}$, respectively, after the SAR images; they arrived at 37 and $191 \mathrm{~min}$. Based on these arrival-time predictions the SAR observations are in good agreement with the moored observations and provide information on spatial distribution of the LIWs. The LIW features 1 and 2 consist of several waves; LIW feature 3 near Site C contains only a few waves. The continuous curved LIW features 3 and 4 suggest that the LIWs generated by flow over Stellwagen Bank may spread radially, resulting in waves moving northwestward (feature 4). It is hypothesized that LIW feature 6 on 17 August located about $9 \mathrm{~km}$ southeast of LT-A is a continuation of this spreading from an LIW formed on the previous tide. If so, these waves are traveling at about $0.3 \mathrm{~m} / \mathrm{s}$. The SAR images suggest that LIWs occur all along the coast near the $40 \mathrm{~m}$ isobath from LT-A south to at least $42^{\circ} \mathrm{N}$. Thus, while the details may change, the basic processes described by the measurements along the MBIWE98 transect are likely to occur along the entire coast. There also appear to be LIWs entering Massachusetts Bay from the Gulf of Maine south of 


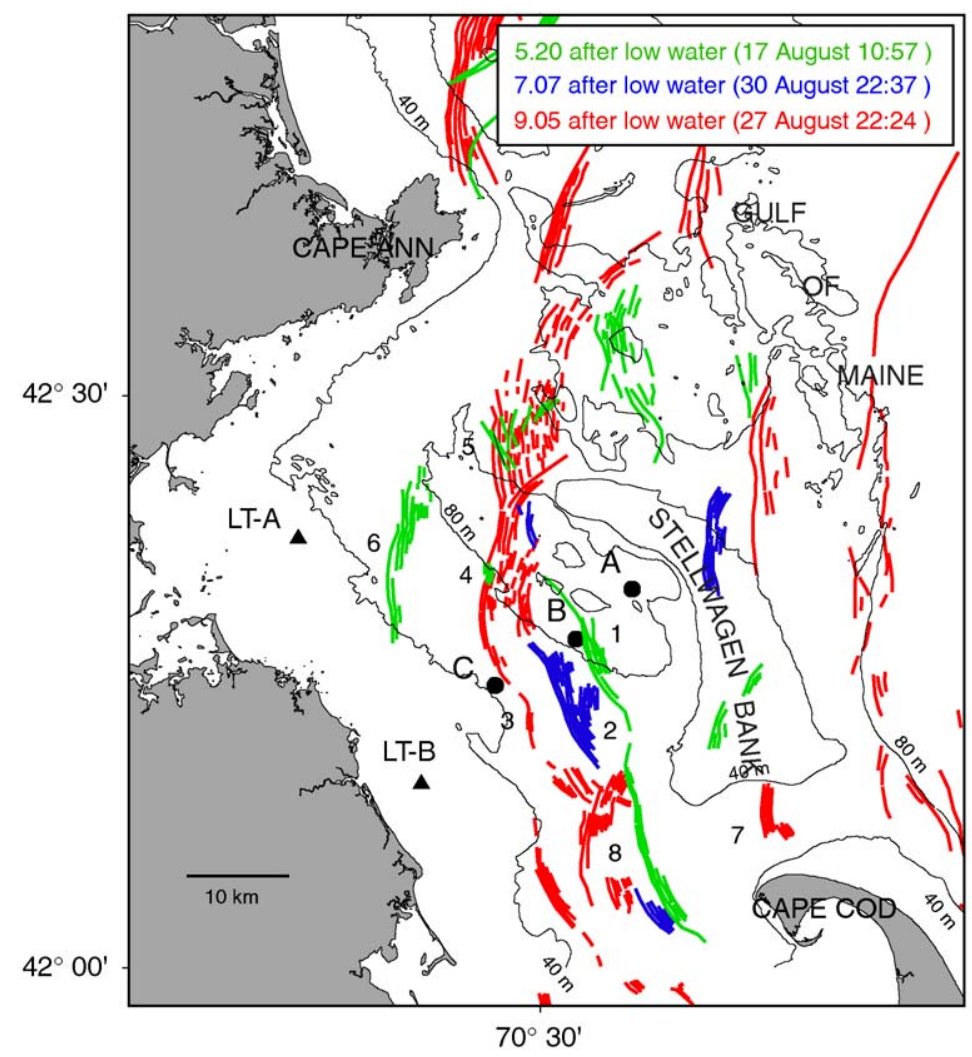

Fig. 8. Composite line drawing of surface features associated with LIWs observed in SAR images obtained on 17, 27 and 30 August 1998 at 5:20, 7:07 and 9:05 h after low water at Site B. See text for discussion of features labeled 1-8. Bathymetric contours are labeled in m.

Cape Ann (feature 5) and north of Cape Cod (features 7 and 8 in Fig. 8). No images were available at times following arrival of the LIWs at Site C (10 h after low water at Site B, Table 1) and thus the existence of LIWs landward of Site C could not be examined.

\subsection{Sediment resuspension and transport by LIWS}

The currents during periods of LIWs were sufficiently strong to cause sediment resuspension at Sites B and C. At Site B sediment resuspension was observed when the current speed exceeded about $0.2 \mathrm{~m} / \mathrm{s}$ at $1 \mathrm{mab}$ (Fig. 7); these speeds were exceeded primarily during the period August 19-24 (Fig. 7b) when the largest near-bottom LIWcurrents were observed. During this period, the beam attenuation measured $1.8 \mathrm{mab}$ increased from a background of about 1.4 to $2-3.51 / \mathrm{m}$ following arrival of the LIWs and remained elevated for $1-2 \mathrm{~h}$. Based on these beam attenuation observations, the concentration of fine-grained sediments in suspension at Site B are most likely a few $\mathrm{mg} / \mathrm{l}$ during the
LIW resuspension events. At Site $\mathrm{C}$, the beam attenuation at $0.54 \mathrm{mab}$ increased a few $0.11 / \mathrm{m}$ during the offshore flow of about $0.35 \mathrm{~m} / \mathrm{s}(6 \mathrm{mab})$ associated with the LIWs. Beam attenuation gradually increased during the flood tide (Figs. 7b,c); this increase is hypothesized to be the onshore advection of turbid offshore water in Stellwagen Basin toward Site C (Fig. 5). The smaller beam attenuation signal at Site C compared to Site B may partially reflect the insensitivity of the beam transmissometer to the coarser sediments at this site ( $80 \%$ sand). In addition, Site $\mathrm{C}$ is located about $400 \mathrm{~m}$ offshore (east) of the sharp transition to highbackscatter intensity material, presumably the gravel pavement that covers the sea floor in water depths shallower than $50 \mathrm{~m}$ (Fig. 4). Thus there is very little fine-grained sediment 'upstream' (onshore) of Site $\mathrm{C}$ available for resuspension and advection past the instrument location (in contrast to Site B). Time-series bottom photographs at Site C show scour of the surficial sediment during the offshore flow events (Fig. 9; see Butman et al. (in press) for additional time-series photographs of the 

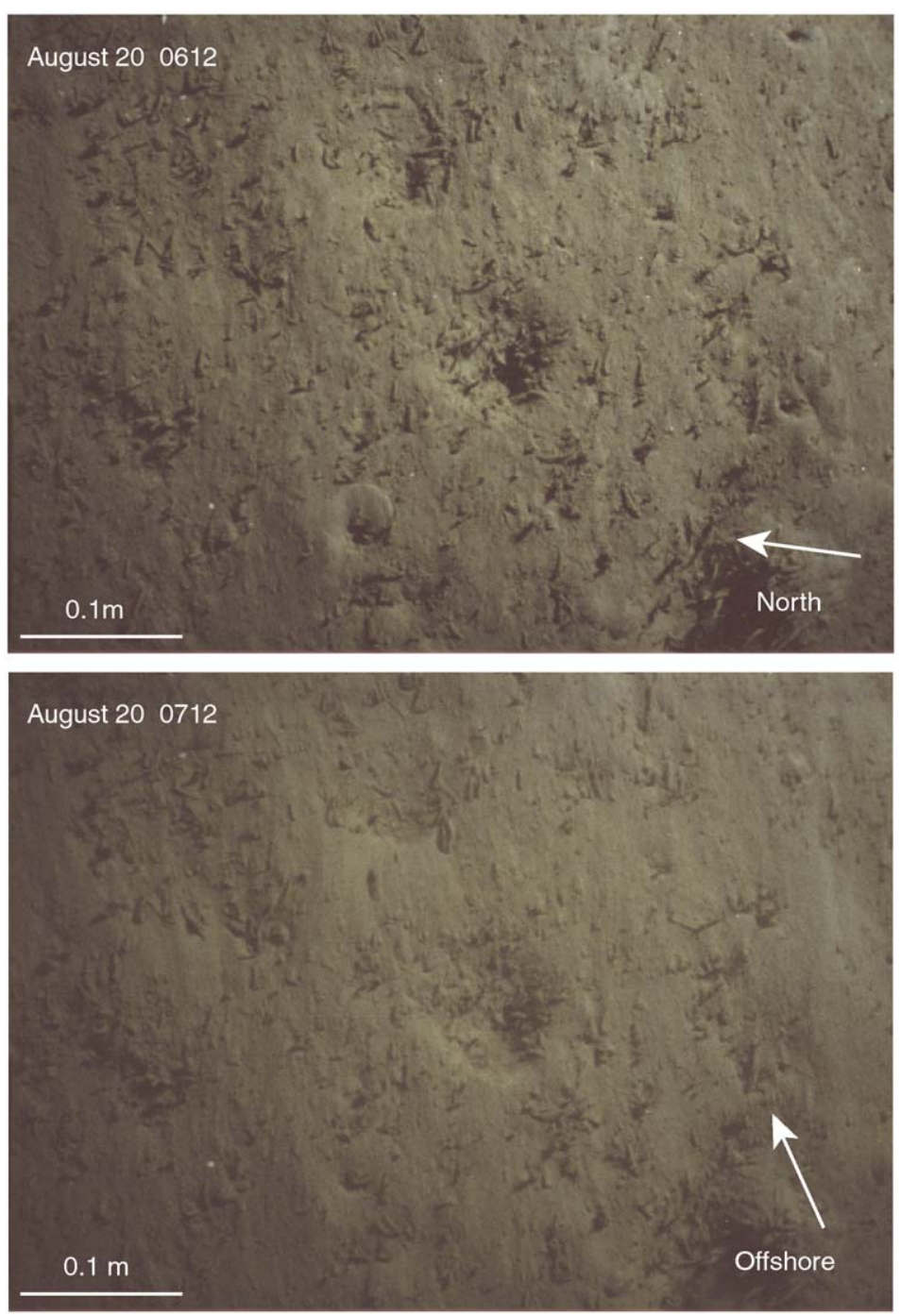

Fig. 9. Sequence of photographs of the sea floor at Site C on August 20, 1998 just before (0612 GMT) and during (0712 GMT) the largest LIW current event observed during MBIWE98 at Site C. The offshore currents associated with the LIW smoothes the sediment surface and enhances subtle linear scour marks perpendicular to the direction of current flow, indicating offshore transport. These features are significantly degraded within $12 \mathrm{~h}$ (just prior to arrival of the next set of waves) by bioturbation. See Fig. $7 \mathrm{~b}$ for times of pictures with respect to bottom current at Site $\mathrm{C}$.

sea floor at Site C). No observations were made at Site A during MBIWE98 to assess sediment resuspension.

At Site $B$, the increase in beam attenuation measured $1.8 \mathrm{mab}$ lagged the increase in current velocity measured $1 \mathrm{mab}$ by about $10 \mathrm{~min}$ (Fig. 7c). This lag is the sum of the time required to vertically mix the resuspended sediments from the sea floor to the transmissometer located $1.8 \mathrm{mab}$, plus the delay in the initiation of sediment resuspension upstream of the observation site due to the propagation of the LIWs. A time scale $T$ for vertical mixing in a steady bottom boundary layer is $H / k u *$, where $k$ is von Karman's constant $(0.41)$ and $u *$ is the bottom friction velocity. For $H$ of $1.8 \mathrm{~m}$ (height of transmissometer) and $u^{*}=0.008 \mathrm{~m} / \mathrm{s}$ (determined assuming a speed of $0.2 \mathrm{~m} / \mathrm{s}$ and a drag coefficient of 0.003 ), the mixing time scale is about $9 \mathrm{~min}$. The sediment observed at the tripod is resuspended at a location UT away (about $90 \mathrm{~m}$ ), where $U$ is the near-bottom current velocity (of order $0.2 \mathrm{~m} / \mathrm{s}$ ). Sediment resuspension begins at this location at a time UT/U $\mathrm{U}_{\text {LIW }}$ after the LIW passes the tripod, where $U_{\text {LIW }}$ is the speed of propagation of the LIWs 
(average at Site B about $0.64 \mathrm{~m} / \mathrm{s}$ ). The sum of the estimates of the vertical mixing lag $(9 \mathrm{~min})$ and the advection lag $(2.3 \mathrm{~min})$ is in good agreement with the observed lag of $10 \mathrm{~min}$.

The sediment resuspension threshold at Site B was about $0.2 \mathrm{~m} / \mathrm{s}(0.18-0.22 \mathrm{~m} / \mathrm{s})$ measured $1 \mathrm{mab}$ (about $0.064 \mathrm{~N} / \mathrm{m}^{2}$ (friction velocity $u^{*}=0.008 \mathrm{~m} / \mathrm{s}$ ) assuming a drag coefficient of 0.003 ) and about 0.35 $\mathrm{m} / \mathrm{s}(0.33-0.38 \mathrm{~m} / \mathrm{s})$ measured at $6 \mathrm{mab}$ at Site $\mathrm{C}$ (Fig. 10). The thresholds were determined from the maximum current speed associated with the first wave in a LIW packet and establishing if sediment resuspension was caused by the LIW as indicated by an increase in the attenuation observed at 1.8 or $0.54 \mathrm{mab}$ at Site B or C, respectively. This strategy was used because the resuspension threshold was often passed (and exceeded) during a single 1-min current measurement, making it impossible to pick an unambiguous threshold value for an individual wave. The resuspension threshold determined at Site B is assumed typical for fine-grained sediments throughout Massachusetts Bay, and is used to determine the frequency of sediment resuspension caused by LIWs and surface waves in this study.

The resuspension threshold was exceeded during 21 of the 49 LIW events observed during MBIWE98 at Site B and during 28 at Site C. During LIW events (defined as the time period beginning just before the first increase in bottom current speed associated with the first wave and continuing for $2 \mathrm{~h}$ ) the bottom current speed exceeded the resuspension threshold about $4.1 \%$ of the time (about $4 \mathrm{~h}$ ) at Site B and about $14 \%$ of the time (about $14 \mathrm{~h}$ ) at Site C (Fig. 11). Over the entire $680 \mathrm{~h}$ data record, the resuspension threshold was exceeded about $0.7 \%$ and $2.2 \%$ of the time at Sites B and C, respectively, $87 \%$ and $93 \%$ of this time during LIW events (Table 1 ).

The net near-bottom transport during LIW events when the current was above threshold was offshore at Sites B and C; the particle excursion at Site B (1 mab) was about $3 \mathrm{~km}$ toward $79^{\circ}$, and the excursion at Site C (6 mab) was about $23 \mathrm{~km}$ toward $62^{\circ}$. These excursions are easily large enough to move particles from the shallow shelf into Stellwagen Basin during a summer season. The offshore particle excursions result from the offshore nearbottom flow associated with the LIWs and the arrival of these waves during eastward (offshore) tidal flow at both Sites B and C.

\subsection{Observations at $L T-A$ and $L T-B$}

Observations at Site LT-A occasionally show the presence of fluctuations with characteristics similar to the LIWs observed in Stellwagen Basin (Fig. 12). However, the arrival of the LIWs was not as

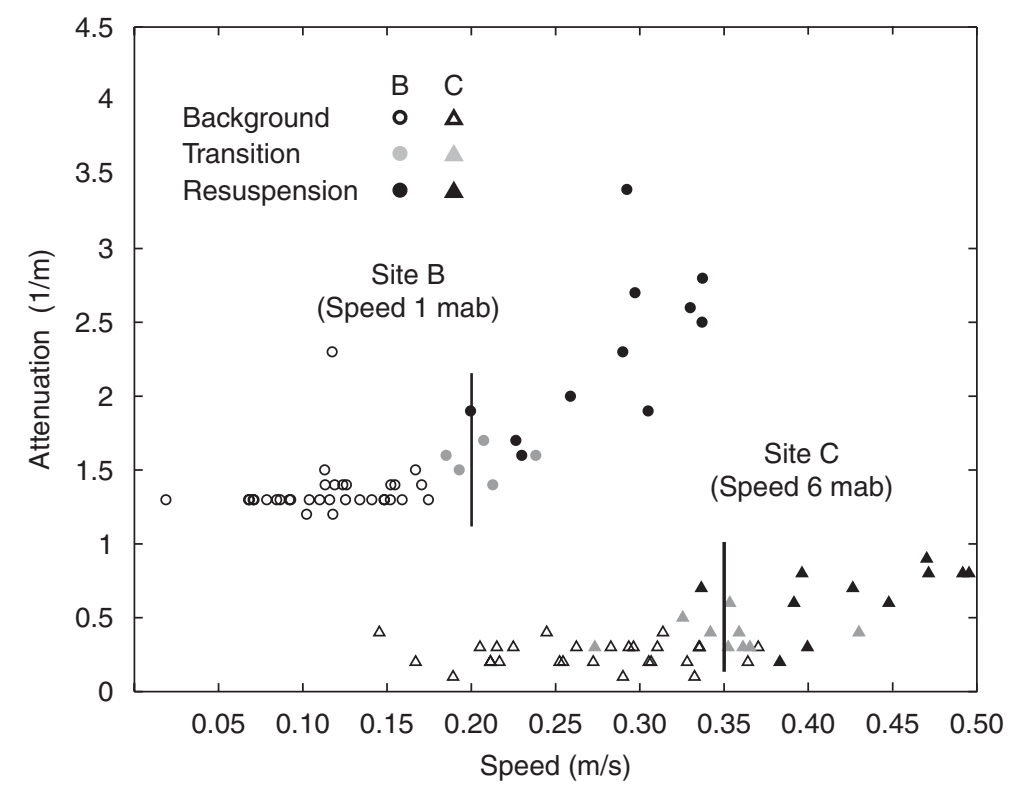

Fig. 10. Speed of first current maximum at Site B (at 1 mab) and Site C (at 6 mab) and associated first maximum in beam attenuation (at $1.8 \mathrm{mab}$ at Site B and $0.5 \mathrm{mab}$ at Site C) for each packet of LIWs. Open symbols indicate LIW currents with no sediment resuspension, gray-filled symbols LIW events with slight resuspension, and black symbols LIW events with resuspension based on beam-attenuation observations. The current threshold for sediment resuspension is approximately $0.2 \mathrm{~m} / \mathrm{s}(1 \mathrm{mab})$ at Site B and $0.35 \mathrm{~m} / \mathrm{s}(6 \mathrm{mab})$ at Site C. 
During LIWs

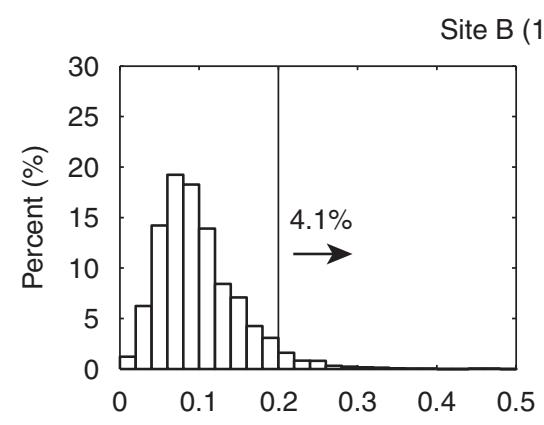

Non-LIW periods

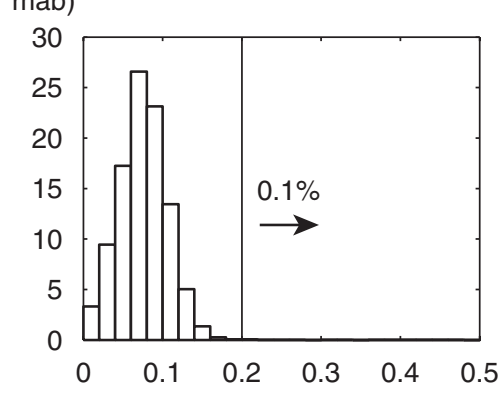

Site C (6 mab)
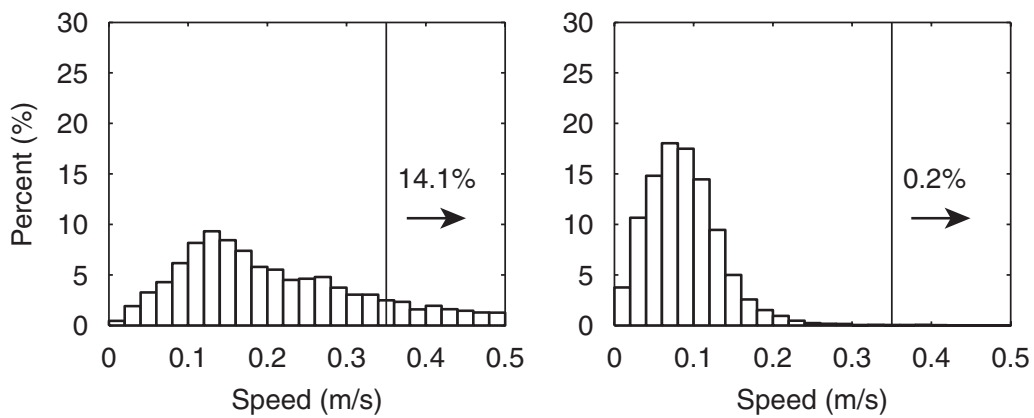

Fig. 11. Histogram of current speeds at Site B (1 mab) and Site C (6 mab) for 2-h period following onset of LIW event (left panel) and during non-LIW periods (right panel). Currents exceeded threshold about 4 and 14\% of the time at Site B and C, respectively, during LIW events and less that $0.2 \%$ of the time during non-LIW event periods.

consistent as at the Stellwagen Basin stations; of the 49 events observed in Stellwagen Basin during MBIWE98 in August 1998, only 13 were evident at LT-A. The current speed during these events was less than $0.2 \mathrm{~m} / \mathrm{s} 1 \mathrm{mab}$ (including the offshore tidal current) and there was no indication of sediment resuspension in the beam attenuation measurements. However, the seafloor at LT-A is a cobble pavement and there is very little fine-grained sediment available for resuspension. The arrival time of these packets was $8.7 \pm 2.5 \mathrm{~h}$ after low water at Site B, or about $1.3 \mathrm{~h}$ earlier than the waves arrive at Site C. The SAR images (Fig. 8) suggest that the LIWs at LT-A could have evolved from those observed along the MBIWE98 transect, but from waves generated two tidal cycles earlier than those observed at Site C. Given the propagation speed of $0.3 \mathrm{~m} / \mathrm{s}$ between features 4 and 6 , the waves would have to slow further to less than $0.2 \mathrm{~m} / \mathrm{s}$ between feature 6 and LT-A to arrive $8.7 \mathrm{~h}$ after low water. The long transit from the generation region and the progressively slower propagation speed could account for the small amplitude and less frequent waves observed at LT-A compared to those along the MBIWE98 transect. Feature 5 (Fig. 8) suggests that LT-A also could also be influenced by waves entering Massachusetts Bay from the Gulf of Maine across the northern end of Stellwagen Bank.

Observations at Site LT-B cannot resolve fluctuations at periods of a few minutes because of the sampling of the ADCP (a $5 \mathrm{~min}$ average obtained every $15 \mathrm{~min}$ ). There is a strong internal tide and a few occurrences of a sudden shear between surface and near-bottom flow were observed. Additional measurements are needed to map the propagation and dissipation of the internal waves from Site C inshore. Scotti and Pineda (2004) have observed strongly nonlinear waves of elevation along the 25$\mathrm{m}$ isobath in this region that are formed when the waves of depression observed at Site $\mathrm{C}$ impinge on the shoaling bottom. The presence of trapped cores in these waves that transport parcels of water shoreward make them a prime candidate for sediment transport. However, at present, it is not known how frequently they develop.

\subsection{Resuspension by surface waves}

Bottom stress $\left(\rho u_{\mathrm{cw}}^{* 2}\right.$, where $u_{\mathrm{cw}}^{*}$ is the currentwave friction velocity) caused by the oscillatory 

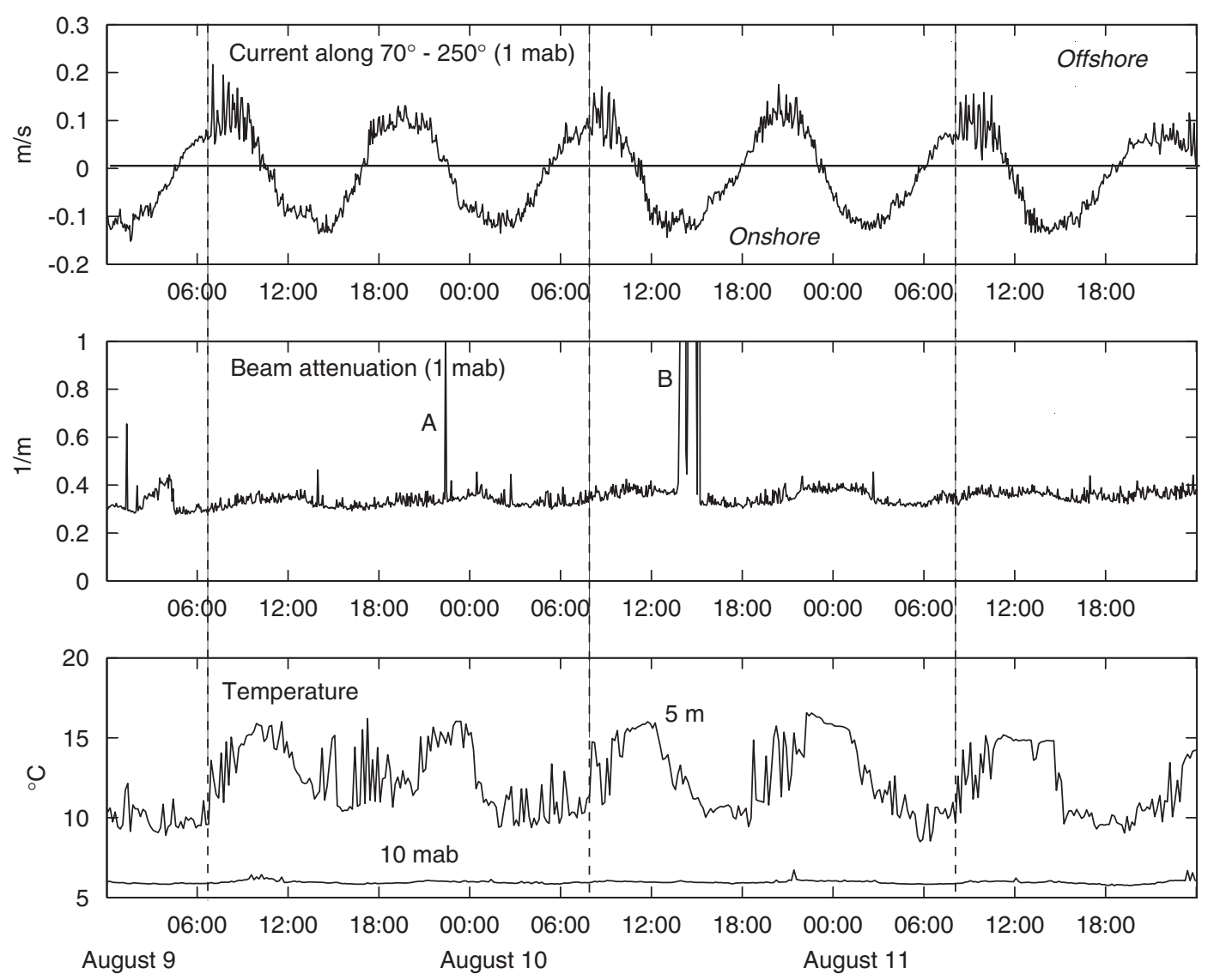

Fig. 12. Time series of current (along $70-250^{\circ}$ ) at $1 \mathrm{mab}$, beam attenuation at $1 \mathrm{mab}$, and temperature at $5 \mathrm{~m}$ and $10 \mathrm{mab}$ at Site LT-A on August 9-11, 1998 (instrument sampling interval $3.75 \mathrm{~min}$ ). Vertical dashed lines mark the beginning of 3 LIW events. Current fluctuations associated with LIWs arrive near maximum ebb tide. An increase in temperature of $3-5^{\circ}$ at $5 \mathrm{~m}$ following arrival of the LIWs indicates depression of the surface layer, as observed at Site B. There is no increase in beam attenuation at 1 mab associated with the LIWs indicating that they are not strong enough to cause sediment resuspension (the sea floor at LT-A is a gravel pavement and only a thin veneer of fine sediments is likely available for resuspension). The increases in beam attenuation labeled A and B are most likely caused by organisms.

currents associated with surface waves and tidal currents was calculated from the wave spectrum collected at NOAA buoy 44013 (Fig. 1) for the period 1996-2005 assuming a bottom roughness of $0.00067 \mathrm{~m}$ (equivalent to a bottom drag coefficient of 0.003 ) and a steady current speed of $0.07 \mathrm{~m} / \mathrm{s}$ at $1 \mathrm{mab}$. The steady current is intended to represent the bottom tidal currents in the central part of Massachusetts Bay of about $0.10 \mathrm{~m} / \mathrm{s}$ (Butman et al., 2005a), adjusted so that squared value of the steady current matches the squared value of the varying current over a tidal cycle. The percent of time that $u_{\mathrm{cw}}^{*}$ exceeded $0.008 \mathrm{~m} / \mathrm{s}$, the critical friction velocity determined from the current measurements in Stellwagen Basin, was larger in winter than in summer and decreased with water depth (Table 1, Fig. 13).
At 25-m water depth, the threshold was exceeded about $39 \%$ of the time (about 71 days) in winter and about $21 \%$ of the time (about 38 days) in summer. At $50-\mathrm{m}$ water depth, $u_{\mathrm{cw}}^{*}$ exceeded $0.008 \mathrm{~m} / \mathrm{s}$ about $11 \%$ of the time (about 20 days) in winter and about $3 \%$ (about 6 days) in summer. At $85-\mathrm{m}$ water depth, $u_{\mathrm{cw}}^{*}$ exceeded threshold less than $2 \%$ of the time (about 3 days) in winter and less than 0.5 days in summer. Only 4 of the 10 summers examined had $u_{\mathrm{cw}}^{*}$ above threshold at $85-\mathrm{m}$ water depth.

\section{Discussion and summary}

Based on the MBIWE98 observations LIWs can be expected to occur across a broad area of Stellwagen Basin and Massachusetts Bay during 


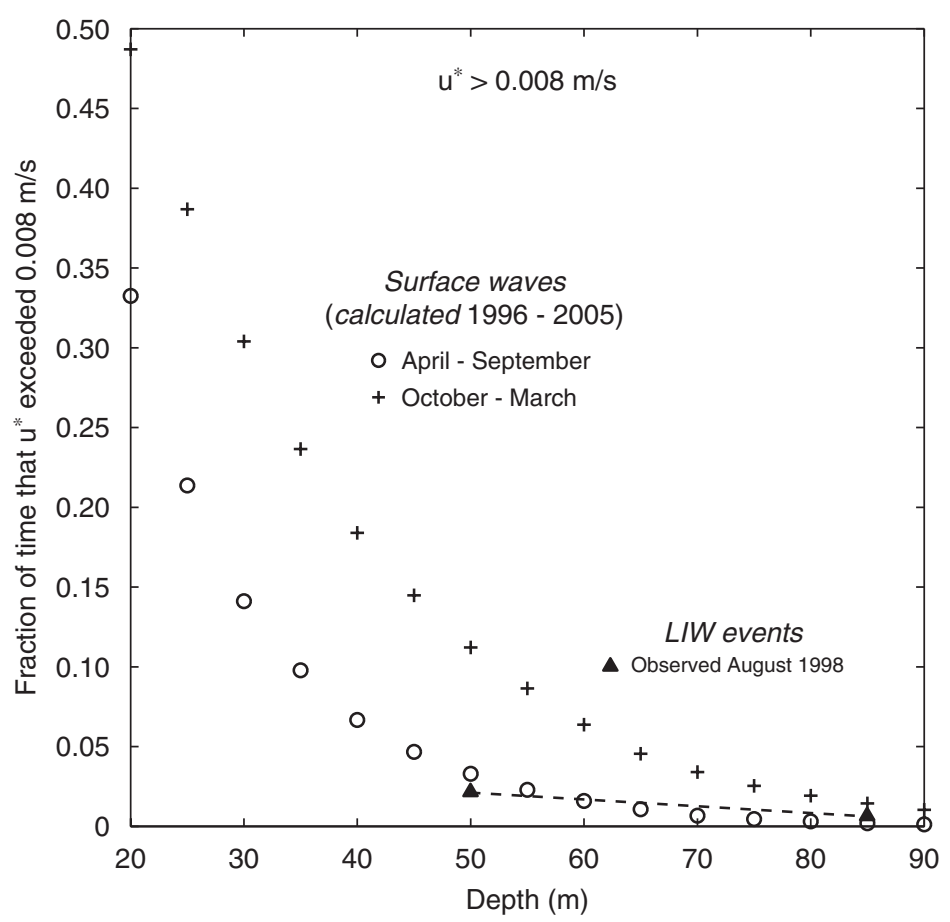

Fig. 13. Percent of time that bottom-friction velocity caused by currents during LIW events (a combination of LIW and tidal current) and by surface waves (plus a $0.10 \mathrm{~m} / \mathrm{s}$ current) exceeds the threshold of $0.008 \mathrm{~m} / \mathrm{s}$ as a function of water depth and season. The LIW line (dashed) shows the percent of time that near-bottom stress caused by LIW events was greater than the resuspension threshold at Site B $(85 \mathrm{~m})$ and $\mathrm{C}(50 \mathrm{~m})$ during MBIWE98. The bottom wave stress was calculated for winter (October through March) and summer (April through September) for the period 1996 through 2005 from the surface wave spectra measured at NOAA Buoy 44,013 and assuming a $0.07 \mathrm{~m} / \mathrm{s}$ steady current $1 \mathrm{mab}$ to simulate the effects of the tidal current. See Table 1.

the summer (Fig. 14). The LIWs are predictably formed every tidal cycle and can be traced from Site A to Site C. Because the LIWs are formed over the generally linear feature of Stellwagen Bank, it is assumed that they also occur to the north and south of the MBIWE mooring transect. The north-south extent of the surface slicks in the SAR images associated with the LIWs in the MBIWE (Fig. 8) supports this assumption. The ubiquitous surface features observed in the SAR images also suggest that LIWs generated in other locations affect Massachusetts Bay; however, their strength and frequency are unknown.

At both Sites B and C, the bottom sediments were episodically resuspended by the offshore nearbottom currents associated with the LIWs superimposed on the offshore-flowing tidal current. The largest near-bottom currents associated with the LIWs were observed on the western shore of Massachusetts Bay at Site C near the 50-m isobath. Near-bottom transport during LIW-induced resuspension at both Sites B and C was offshore. At Site A the LIWs arrive during the flood (westward- flowing) tide, so the speed of the offshore (eastward) near-bottom current associated with the LIWs would be reduced by the tidal current (about $0.1 \mathrm{~m} / \mathrm{s}$ ), most-likely reducing the frequency and intensity of LIW-induced resuspension in the eastern part of Stellwagen Basin. The near-bottom LIW currents begin to add to the offshore tidal flow near Site B. LIWs were observed at LT-A at 34-m water depth, but they were less frequent and not as predictable as in Stellwagen Basin and the currents during LIW events were not strong enough to resuspend sediments. Sediment resuspension by LIWs in water depths shallower than $50 \mathrm{~m}$ in the region to the west of the MBIWE transect remains to be explored.

In the deeper parts of Stellwagen Basin, sediment resuspension by LIWs or by surface waves is infrequent (Figs. 13 and 14, Table 1). For example, in summer at 85-m water depth, sediment resuspension was caused by LIWs about $0.7 \%$ of the time and by surface waves about $0.2 \%$ of the time. In winter at $85-\mathrm{m}$ water depth, sediment resuspension was caused by surface waves less than $2 \%$ of the 


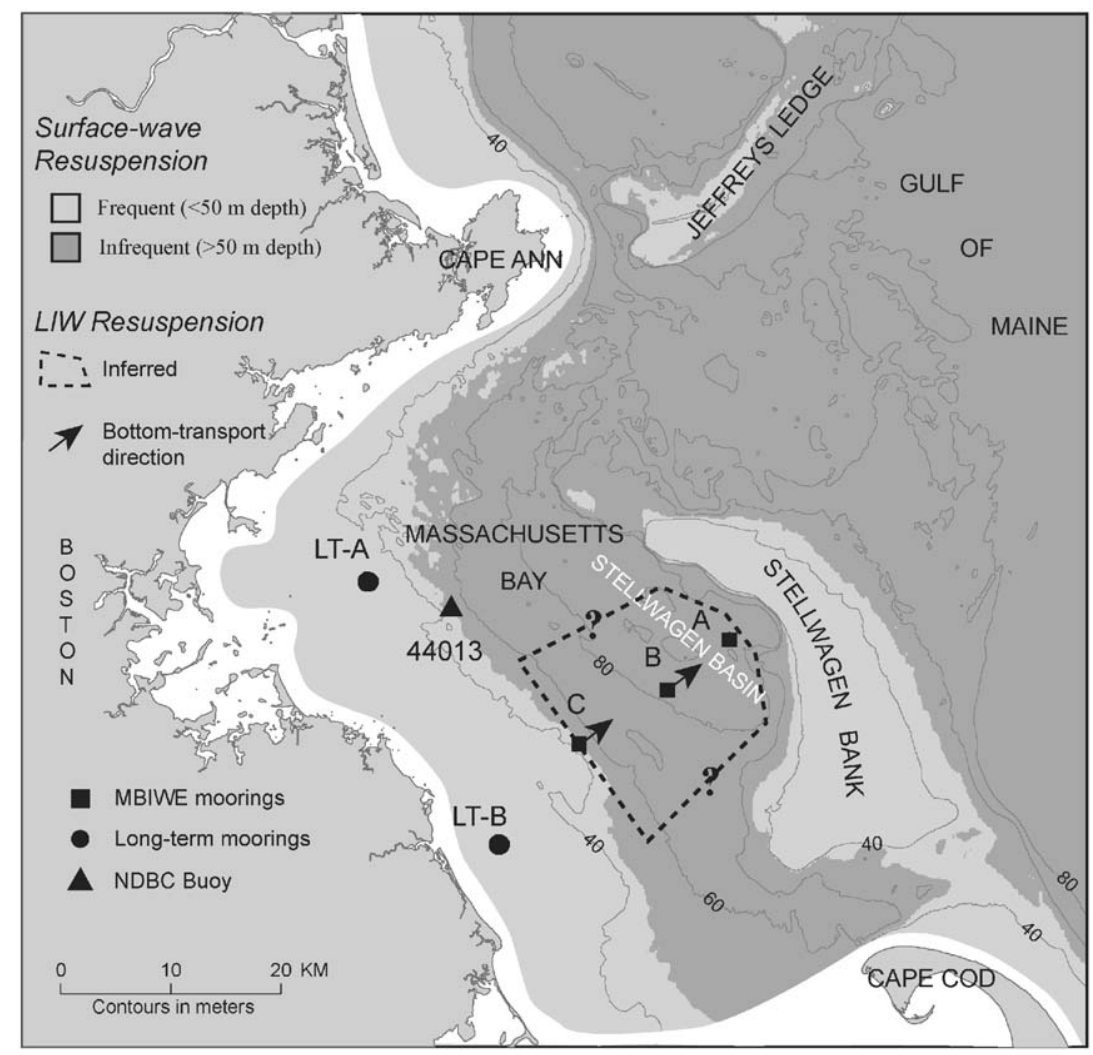

Fig. 14. Map of Massachusetts Bay summarizing areas affected by resuspension caused by LIWs and surface waves. The area affected by LIWs in summer generated by tidal flow across Stellwagen Bank, based on observations in MBIWE98, is outlined by the dashed black line. The extent of this area is somewhat uncertain, as indicated by question marks at the northern and southern boundaries. SAR images (Fig. 8) suggest that other areas of Massachusetts Bay may also be affected by LIWs. Arrows at Sites B and C show inferred direction (offshore) of near-bottom sediment transport caused by the LIWs at these locations. Areas that are predicted to experience sediment resuspension by surface waves more than about $10 \%$ of the time in winter (water depths shallower than $50 \mathrm{~m}$ ) are shown in light gray; areas relatively unaffected by surface waves that experience resuspension less than about $10 \%$ of the time in winter (water depths greater than $50 \mathrm{~m}$ ) are shown in dark gray. This analysis assumes that the surface waves measured at the NOAA buoy are representative of the waves throughout Massachusetts Bay and the western Gulf of Maine.

time. Although observations of the MBIWE were limited to August, LIWs are likely to be present for perhaps two months during the year, from mid-July to mid-September, when the water column is stratified. Over an entire year, resuspension at $85-\mathrm{m}$ water depth is estimated to be caused by surface waves about 3 days during winter (October through March), by surface waves about 0.4 days in summer (between April and September), and by LIWs about 0.4 days in summer (between mid-July and mid-September). An important difference between LIW and surface wave-induced resuspension is the duration, frequency, and spatial extent of the event. At a fixed location, LIW-induced a sediment resuspension may occur for only a few minutes each day, but in total LIWs may resuspend sediments for 5 hours or so each tidal cycle as they transit westward across Stellwagan Basin. In contrast, surface-wave induced resuspension may occur across the entire basin for several hours during infrequent stroms. LIW-induced resupension most likely occurs every summer, whereas surface-wave induced resuspension may only occur every few years during large storms. The most tranquil period is spring (April, May and June) when the surface waves are small and LIWs do not occur. The infrequent resuspension of bottom sediments in winter and summer is consistent with the accumulation of fine-grained sediments in Stellwagen Basin.

This study provides insight into the importance of sediment resuspension and transport caused by surface and internal waves to the formation of the transition from coarse to fine-grained sediment at about 50-m water depth along the western shore of 
Massachusetts Bay. The frequency of surface-wave resuspension in winter decreases across this transition from about $18 \%$ at the $40-\mathrm{m}$ isobath to about $6 \%$ at the $60-\mathrm{m}$ isobath (a distance of about $2 \mathrm{~km}$ ). The wind-driven near-bottom flow when surface waves are largest (winds from the northeast) is expected to have a downwelling (offshore) component that would transport resuspended sediment offshore. The sediment transition is also where the currents associated with LIWs observed in MBIWE98 had the highest percentage of currents above the resuspension threshold; the net nearbottom flow was also offshore during these events. Dissipation of LIWs shoreward of this water depth may increase near-bottom resuspension. Thus both LIWs and surface waves exhibit onshore-offshore gradients in the frequency of resuspension as well as an offshore flow during resuspension that would winnow fine-grained sediments from the landward side of the transition and deposit them on the seaward side. Further investigation would explore the rates of sediment transport caused by LIWs and winter storms, not just the frequency of resuspension as presented here, as well as the fate of the LIWs shoreward of the 50-m isobath.

\section{Acknowledgments}

MBIWE98 was carried out cooperatively by investigators at the US Geological Survey (USGS) and the Woods Hole Oceanographic Institution (WHOI). J. Borden, W. Strahle, and M. Martini (USGS), and W. Ostrom and B. Way (WHOI) prepared and deployed the moored array. M. Bothner provided encouragement throughout this project, insight on sediment geochemistry, and the transmissometer calibration based on the pumped water samples at LT-A; he also led mooring cruises to deploy and recover moorings at LT-A and LT-B. F. Lightsom processed the time-series data. C. Sherwood and R. Signell provided advice and assistance with the bottom stress calculations under wave and current conditions and C. Sherwood provided Matlab routines to calculate bottom velocities from the surface-wave spectra and bottom stress based on Madsen (1994). C. Jackson (Global Ocean Associates) provided assistance with the SAR image interpretation in connection with the Internal Wave Atlas Project supported by the Office of Naval Research (ONR) (see http://www.internalwaveatlas.com/Atlas2_index.html). R. Limeburner assisted in collection of the hydrographic data. The manuscript benefited from reviews by A. Ogston and from two anonymous reviewers. We thank the Captains and crews of the RV Argo Maine and FV Christopher Andrew for deployment and recovery of instrumentation and help on the hydrographic surveys. MBIWE98 was supported by the USGS and the Office of Naval Research (ONR). The longterm observations at LT-A and LT-B were conducted under a Joint Funding Agreement between the USGS and the Massachusetts Water Resources Authority and an Inter-Service Agreement with the US Coast Guard. A. Scotti received support from the WHOI Postdoctoral Scholar program, the Johnson Foundation, the USGS, and ONR through grant N00014-01-1-0172; R. Beardsley through ONR grants N00014-98-1-0059, N00014-00-1-0210 and the WHOI Smith Chair in Coastal Physical Oceanography; and S. Anderson through ONR grant N000140-97-1-0158.

\section{References}

Baker, E.T., Lavelle, J.W., 1984. The effect of particle size on the light attenuation coefficient of natural suspensions. Journal of Geophysical Research 89 (C5), 8197-8203.

Bogucki, D., Dickey, T., Redekopp, L.G., 1997. Sediment resuspension and mixing by resonantly generated internal solitary waves. Journal of Physical Oceanography 27, 1181-1196.

Butman, B., 1987. Physical processes causing sediment movement. In: Backus, R.H. (Ed.), Georges Bank. MIT Press, Cambridge, MA, pp. 147-162.

Butman, B., Alexander, P. Soupy, Anderson, S.P., Lightsom, F.L., Scotti, A., Beardsley, R.C., 2006. The Massachusetts Bay Internal Wave Experiment, August 1998: Data Report. US Geological Survey Data Series 85. US Geological Survey, Woods Hole, MA. DVD-ROM. Online at <http://pubs. usgs.gov/ds/2006/85>.

Butman, B., Bothner, M.H., Alexander, P. Soupy, Lightsom, F.L., Martini, M.A., Gutierrez, B.T., Strahle, W.S., 2004b. Long-term oceanographic observations in western Massachusetts Bay offshore of Boston, Massachusetts: Data Report for 1989-2002. US Geological Survey Digital Data Series DDS74, Version 2.0. US Geological Survey, Woods Hole, MA. DVD-ROM. Online at 〈http://pubs.usgs.gov/dds/dds74/ $\rangle$.

Butman, B., Noble, M.A., Folger, D.W., 1979. Long-term observations of bottom current and bottom sediment movement on the Mid-Atlantic continental shelf. Journal of Geophysical Research 84, 1187-1205.

Butman, B., Signell, R.P., Warner, J.C., Alexander, P.S., 2005a Oceanographic Setting. Section 4 in: Bothner, M.H., Butman, B. (Eds.), Processes Influencing the Transport and Fate of Contaminated Sediments in the Coastal Ocean-Boston Harbor and Massachusetts Bay. US Geological Survey Open-File Report 2005-1250. US Geological Survey, Woods Hole, MA. Online at 〈http://pubs.usgs.gov/of/2005/1250/ index.html $>$. 
Butman, B., Valentine, P.C., Danforth, W.W., Hayes, L., Serrett, L.A., Middleton, T.J., 2004a. Shaded relief, backscatter intensity and sea floor topography of Massachusetts Bay and the Stellwagen Bank region, offshore of Boston, Massachusetts. US Geological Survey Geologic Investigation Map I-2734, scale 1:125,000, 2 sheets. US Geological Survey, Reston, VA. Online at $\langle$ http://pubs.usgs.gov/imap/i2734/>.

Butman, B., Warner, J.C., Bothner, M.H., Alexander, P.S., 2005b. Predicting the transport and fate of sediments caused by northeast storms. Section 6 in: Bothner, M.H., Butman, B. (Eds.), Processes Influencing the Transport and Fate of Contaminated Sediments in the Coastal Ocean-Boston Harbor and Massachusetts Bay. US Geological Survey Open-File Report 2005-1250. US Geological Survey, Woods Hole, MA. Online at <http://pubs.usgs.gov/of/2005/1250/ index.html $>$.

Cacchione, D.A., Pratson, L.F., Ogston, A.S., 2002. The shaping of continental slopes by internal tides. Science 296 , 724-727.

Chereskin, T.K., 1983. Generation of internal waves in Massachusetts Bay. Journal of Geophysical Research 88, 2649-2661.

Crusius, J., Bothner, M.H., Sommerfield, C.K., 2004. Bioturbation depths, rates and processes in Massachusetts Bay sediments inferred from modeling of ${ }^{210} \mathrm{~Pb}$ and ${ }^{239+240} \mathrm{Pu}$ profiles. Estuarine, Coastal and Shelf Science 61 (4), 643-655.

Gasparovic, R.F., Apel, J.R., Thompson, D.R., Tochko, J.S., 1986. A comparison of SIR-B synthetic aperture radar data with ocean internal wave measurements. Science 232, 1529-1531.

Gasparovic, R.F., Apel, J.R., Kasischke, E.S., 1988. An overview of the SAR internal wave signature experiment. Journal of Geophysical Research 93 (C10), 12304-12316.

Global Ocean Associates, 2004. An atlas of internal solitary-like waves and their properties, second ed. Global Ocean Associates, Alexandria, VA http://www.internalwaveatlas. com/Atlas2_index.html.

Grosenbaugh, M., Anderson, S., Trask, R., Gobat, J., Paul, W., et al., 2002. Design and performance of a horizontal mooring for upper ocean research. Journal of Atmospheric and Oceanic Technology 19, 1376-1389.

Gutierrez, B.T., Butman, B., Blackwood, D.B., 2001. Photographs of the sea floor in western Massachusetts Bay. US Geological Survey Open-File Report 00-427. US Geological Survey, Woods Hole, MA. CD-ROM. Online at <http:// pubs.usgs.gov/of/of00-427/>.

Halpern, D., 1971. Observations of short-period internal waves in Massachusetts Bay. Journal of Marine Research 29, 116-132.

Harris, C.K., Butman, B., Traykovski, P., 2003. Winter-time circulation and sediment transport in the Hudson Shelf Valley. Continental Shelf Research 23 (8), 801-820.

Haury, L.R., Briscoe, M.G., Orr, M.H., 1979. Tidally generated internal wave packets in Massachusetts Bay. Nature 278, 312-317.

Haury, L.H., Wiebe, P.H., Orr, M.H., Briscoe, M.G., 1983. Tidally generated high-frequency internal wave packets and their effects on plankton in Massachusetts Bay. Journal of Marine Research 41, 65-112.

Johnson, D.R., Weidemann, A., Pegau, W.S., 2001. Internal tidal bores and bottom nepheloid layers. Continental Shelf Research 21, 1473-1484.
Klymak, J.M., Moum, J.N., 2003. Internal solitary waves of elevation advancing on a shoaling shelf. Geophysical Research Letters 30 (20), 2045.

Knebel, H.J., Circe, R.C., 1995. Seafloor environments within the Boston Harbor - Massachusetts Bay sedimentary system: a regional synthesis. Journal of Coastal Research 11, 230-251.

Madsen, O.S., 1994. Spectral wave-current bottom boundary layer flows. Coastal Engineering 1994. In: Proceedings, 24th International Conference, Coastal Engineering Research Council/ASCE, pp. 384-398.

Moody, J.A., Butman, B., Bothner, M.H., 1987. Near-bottom suspended matter concentration during storms: estimates based on in situ observations of light transmission and a particle size dependent transmissometer calibration. Continental Shelf Research 7, 09-628.

Noble, M.A., Xu, J.P., 2003. Observations of largeamplitude cross-shore internal bores near the shelf break, Santa Monica Bay, CA. Marine Environmental Research 56, 127-149.

Pineda, J., 1991. Predictable upwelling and shoreward transport of planktonic larvae by internal tidal bores. Science 253, 548-551.

Poppe, L.J., Eliason, A.H., Fredericks, J.J., Rendigs, R.R., Blackwood, D., Polloni, C.F., 2000. Grain-size analysis of marine sediments - methodology and data processing. Chapter 1 in: Poppe, L.J., Polloni, C.F. (Eds.). USGS East-Coast Sediment Analysis: Procedures, Database and Georeferenced Displays. US Geological Survey Open-File Report 00-358. US Geological Survey, Woods Hole, MA. DVD-ROM. Online at $\langle$ http://pubs.usgs.gov/of/of00-358/〉.

Ravizza, G.E., Bothner, M.H., 1996. Osmium isotopes and silver as tracers of anthropogenic metals in sediments from Massachusetts and Cape Cod Bays. Geochimica et Cosmochimica Acta 60, 2753-2763.

Scotti, A., Pineda, J., 2004. Observation of very large and steep internal waves of elevation near the Massachusetts Coast. Geophysical Research Letters 31, L22307.

Scotti, A., Butman, B., Beardsley, R.C., Alexander, P.S., Anderson, S., 2005. A lagged beam-to-earth transformation to measure short-wavelength internal waves with an Acoustic Doppler Current Profiler (ADCP). Journal of Atmospheric and Oceanic Technology 22, 583-591.

Shepard, F.P., 1954. Nomenclature based on sand-silt-clay ratios. Journal Sedimentary Petrology 24, 151-158.

Trask, R.P., Briscoe, M.G., 1983. Detection of Massachusetts Bay internal waves by the Synthetic Aperture Radar (SAR) on SEASAT. Journal of Geophysical Research 88, 1789-1799.

Tucholke, B.E., Hollister, C.D., 1973. Late Wisconsin glaciation of the southwestern Gulf of Marine: New evidence from the marine environment. Geological Society of America Bulletin 84, 3279-3296.

Valentine, P.C., Blackwood, D.B., Parolski, K.F., 2000. Seabed Observation and Sampling System. US Geological Survey Fact Sheet FS-142-00. US Geological Survey, Woods Hole, MA. Online at <http://pubs.usgs.gov/fs/fs142-00/fs142-00. pdf $>$.

Wiberg, P.L., Drake, D.E., Cacchione, D.A., 1994. Sediment resuspension and bed armoring during high bottom stress events on the northern California continental shelf: measurements and predictions. Continental Shelf Research 14 (10/11), 1191-1291. 